MANCHESTER

1824

\title{
Economics
}

Discussion Paper Series

EDP-1310

\section{Bidding Behavior given Point and Interval Values in a Second-price Auction}

\author{
Prasenjit Banerjee \\ Jason F. Shogren
}

July 2013

Economics

School of Social Sciences

The University of Manchester

Manchester M13 9PL 


\title{
Bidding Behavior given Point and Interval Values In a Second-price Auction*
}

\author{
Prasenjit Banerjee $^{\mathrm{a}}$ and Jason F. Shogren ${ }^{\mathrm{b}}$
}

8 July 2013

(revision requested by Journal of Economic Behavior and Organization)

\begin{abstract}
Although rational choice theory presumes people have a point estimate of their willingness to pay (WTP) for a good or service, the idea of coherent arbitrariness suggests they have an interval of values. Herein we explore bidding behavior in a second-price auction in which bidders have point or interval values and point or interval bidding. We find bidders bid rationally: (i) when bidders have a point value but are asked to state an interval bid, they choose to bid as an interval with the point value as the mean of the interval; (ii) bidders who had a value interval but are asked to bid as a point estimate bid the expected value from the interval; and (iii) bidders with an interval value and who bid an interval again bid sincerely.
\end{abstract}

Key Words: second price auction, bidding behavior, preference elicitation, interval values

JEL Code: C91, D44, D46, Q51

a (Corresponding Author) University of Manchester, Economics, Oxford Road, Manchester, M13 9PL, UK. Ph: +44(0)1613066916. Fax: +44(0)1612754812. Email: prasenjit.banerjee@manchester.ac.uk.

${ }^{\mathrm{b}}$ University of Wyoming, Economics, Laramie, Wyoming, 82072, USA

*We thank the Bugas and Stroock funds for the partial financial support, the reviewers and Nicolas Jacquemet for their useful comments, and Pritam Gupta and Amrita Mukherjee for laboratory assistance. Shogren thanks the Norwegian University of Life Sciences for the support. 


\section{Introduction}

Rational choice theory presumes people have a point estimate of their value for a good and service, and they can translate this value into a single monetary willingness to pay (WTP) statement (Marshall, 1890; Ciriacy-Wantrup, 1947; Bateman and Willis, 1999; Bockstael and McConnell, 2005). In contrast, work in behavioral economics has challenged this idea of a precise point estimate with a psychological notion codified as coherent arbitrariness (Ariely et al., 2003). Coherent arbitrariness suggests it is more likely that people have a range of acceptable values, such that asking for one single point estimate of WTP could well be biased due to the person anchoring on some arbitrary cue (e.g., Kahneman and Sugden, 2005; Manski and Molinari, 2010). As stated in Ariely et al.'s (2003) paper on the consequences of coherent arbitrariness: "rather than specific WTP values for products, consumers probably have some range of acceptable values." Their speculation on the question of point versus interval values matters for work on non-market valuation that elicits preferences for, say endangered species protection or water quality (see Hanley et al., 2009). A typical preference elicitation survey asks people to state their preferences for non-market goods presumes people have a well-formed point estimate of value. The reality, however, is most people have little experience about how to form a point value or a range of values for these non-market goods, and then how to translate these values into a stated willingness to pay (see Shogren, 2005).

In response, several methods in the preference elicitation literature have emerged to address the general question of "value uncertainty" in different ways, including a fuzzy number approach to represent the vagueness of preference (Kooten, Kckmar, and Bulte, 2001), or adding a random number in the utility function (Haneman and Kristrom, 1995), allowing subjects to state explicitly how certain or uncertain they are about their point estimate (Blumenschein et al. 
2008), or asking people to take a truth-telling oath that commits them to their point estimate (Jacquemet et al., 2013). All this work, however, presumed the person still preferred to and could state a point estimate of value albeit with a confidence interval to capture the uncertainty. In contrast, Hanley et al. (2009) explicitly examine whether people prefer to state a point over an interval value, or visa versa. They designed a survey to explore the empirical validity of these two polar viewpoints on preferences — point vs interval values — for an environmental good. Valuing improved water quality for a coastal town in Scotland, they allow people to choose how to state their WTP — either as a point estimate or as an interval of values. Their findings do not contradict coherent arbitrariness - many people preferred to express their value as an interval, especially those less familiar with the good (also see Flachaire and Hollard, 2007).

Herein we design an induced valuation experiment to explore bidding behavior in a second-price auction when bidders have interval values or interval bidding possibilities, or both (see Lusk and Shogren, 2007, for an overview on experimental auctions and preference elicitation). We follow the tradition of using experimental auctions used demand-revealing (in theory) exchange institution for market goods (e.g., art, baseball cards, pollution permits) and non-market environmental goods (see for example Hoffman et al. 1993; Fox et al. 1998; Shogren et al. 1994; Plott and Zeiler, 2005). There is less experimental work, however, that has explored the behavioral underpinnings in stated demand when value is uncertain. Table 1 summarizes the work examining bidding behavior in auctions in the field and lab given value uncertainty. Our work differs from this previous work given (i) we allow bidders to choose their bid in point estimate or in interval in a weakly demand revealing auction; and (ii) we consider uncertainties over private values (using interval value) and market prices (interval bids). 
We develop a 2x2 experimental design—-point or interval values, and point or interval bidding to address three main questions. First, how do rational bidders bid if we treat them like behavioralist with coherent arbitrariness when in fact they are not (point value/interval bid)? In rational choice theory, a bidder has a weakly dominant strategy of bidding a point equal to his or her induced point value - regardless of whether he or she is asked to state a point or an interval (an interval can be stated as a point, e.g., \$40-\$40). If we ask for an interval bid, and we get an interval back from people with a point value, this suggests people might prefer the flexibility of the interval (or an experimental demand effect). Our results suggest our bidders choose to bid an interval, not a point. Interestingly though, the typical bidder seemed rational or "coherent"he or she formed the interval bid by using the induced point value as the mean of the interval.

Second, what if we treat people as rational but their preferences are coherently arbitrary? We address this by examining how bidders bid if they have a value interval but are asked to state a point estimate - the classic stated preference method. Given uniform distribution of values and assuming risk neutrality, we predict a bidder would select his bid where his expectation of given interval value equates the bid. Our results suggest bidders bid their expected value from the interval. Third, how do bidders bid address if they have an interval value and they state an interval bid? Assuming risk neutrality, we have two symmetric equilibria - (1) bid in interval equating the expectation of the interval bid with the induced value; and (2) bid in point equal to the expected interval value. Again, our bidders bid sincerely - even with interval values, as measured by equality in the expected values of the bid and value intervals.

Overall, our results suggest using interval bidding procedures in field non-market valuation settings might be viable. We recognize our case is a simplification-(i) our bidders use mean/median as reference points given values are drawn from a uniform distribution; and (ii) we 
assume bidders are risk neutral. In applying the interval method in the field, people will use a variety of internal reference points to construct their point estimates for homegrown values. Also, risk preference could play a role when people have range of values in their mind. Future work would explore these issues.

\section{Analytical Framework: Bidding with and without intervals}

We consider rational bidding behavior in our 2x2 treatments: Point/point bid; Point value/interval bid; Interval value/point bid; and Interval value/interval bid.

\section{Point Value/Point Bid}

Bidding behavior within the classic Vickrey second-price auction is well-known to be weakly demand revealing in theory (Vickrey, 1961). We repeat the logic to establish our baseline model. Nature selects private value $v$ for $k$ bidders. Each bidder submits his bid, $b$, and the bids are ranked from highest to lowest. The highest bidder wins and pays the second highest bid. The bidder $k$ 's payoff, $\pi$, is:

$$
\pi_{k}=v_{k}-p \text { if } b_{k}>p \text { and } \pi_{k}=0 \text { if } b_{k} \leq p
$$

where $p$ is second highest bid, $b_{k}$ is bidder $k$ 's bid, and $v_{k}$ is his value. The bidder's incentive is to bid his value since overbidding risks paying too much and underbidding risks missing out on a profitable opportunity (see, Milgrom and Weber 1982).

\section{Point Value/Interval Bid}

When people are asked to submit bids in intervals given they have a point value, rational bidders have two choices: (1) bid a range or a point; and (2) bid sincerely or not. In theory, if they believe the other bidders are rational, each bidder should bid a point equal to their point value. To see this, assume nature selects a private value $v$ for each of $k$ bidders and each bidder 
submits his bid in a range, $b \in\left\{b_{\min }, b_{\max }\right\}$. Bidders can submit their bids in one single number too. In that case, the upper and lower bound of the interval bid coincide (i.e. $b_{\min }=b_{\max }=b$ ). Bids are ranked from highest to lowest based on one random number drawn from the submitted interval bids. Again highest bidder wins and pays second highest bid, $p$. The bidder $k$ buys the good if the random number drawn from his range, $\hat{b}_{k}$, exceeds the market price, $\hat{b}_{k}>p$. The payoff, $\pi$, conditional on the draw $\hat{b}_{k}$, is same as expressed in equation (1), $\pi_{k}=v_{k}-p, \pi_{k}>0$ if $\hat{b}_{k}>p$ and $\pi_{k}=0$ if $\hat{b}_{k} \leq p$.

The basic bidding logic is similar to the point-point auction—it is a suboptimal strategy for a rational bidder to choose his interval bid higher $\left(b_{k_{\min }}>v_{k}\right)$ or lower $\left(b_{k_{\max }}<v_{k}\right)$ than the value. Now we explain why bidding the point value is optimal. Suppose bidder $k$ bids in interval, $\left(b_{k_{\min }}, b_{k_{\max }}\right)$, and this interval bid contains his value, $v_{k}$. The possible outcomes are: (1) Win with a positive profit: If $p<\hat{b}_{k}<v_{k}$. Bidding point and bidding interval would give him the same payoff. However, bidding true value might not give him the same outcome if $\hat{b}_{k}>v_{k}>p$. (2) Win with a negative profit: If $v_{k}<p<\hat{b}_{k}$. He would be better off by bidding his point value. (3) Lose the auction: If $p>\hat{b}_{k}>v_{k}$. He gains nothing extra by bidding his value. But, if $v_{k}>p>\hat{b}_{k}$, then the bidder loses the good because the random draw from his interval bid is less than the market price. He could win by bidding his value. It is suboptimal for the bidder to choose the lower bound of the interval bid less than the value.

Therefore the strategy of bidding the true value weakly dominates over bidding interval, even if the interval bid contains the true value. However, a bidder could increase the chance of winning the auction by choosing an interval with an upper end higher than the value and the lower end is the given value. As he pays the second highest bid, this interval bid would not have any real cost (Kagel, 1995). 


\section{Interval Values/Point Bid}

Predicting rational bidding behavior is less straightforward when people have interval values and they have to bid in one single number. Now risk preferences could play a role. Assume nature selects an interval of private values $v \in\left\{v_{\min }, v_{\max }\right\}$, for $i$ th bidder, $i=1,2, \ldots$, $k$. Bidders submit their point bid, $b$, and the highest bidder buys the good and pays the second highest bid, $p$. Highest bidder's payoff depends on a number randomly drawn from his range of values. If $\hat{v}_{k}$ is the random number drawn from $k$ th bidder's interval value, $\left\{v_{k_{\min }}, v_{k_{\max }}\right\}$, and $b_{k}$ is his point bid, then the payoff, $\pi_{k}$, conditional on the draw $\hat{v}_{k}$, is same as expression (1): $\pi_{k}=\hat{v}_{k}-p, \pi_{k}>0$ if $b_{k}>p$ and $\pi_{k} \leq 0$ if $b_{k}<p$. Assuming the values are from a uniform distribution, any number within the range of values is equally likely to be drawn from the range.

A bidder, say bidder $k$, has two choices-bid within $\left\{v_{k_{\min }}, v_{k_{\max }}\right\}$, or bid outside the value range. He has no incentive to bid lower than the interval value, i.e., $b_{k}<v_{k_{m i n}}$, as it would only increase the chance of losing the auction. If he bids higher than the interval value, i.e., $b_{k}>v_{k_{\max }}$, then the possible outcomes are: (1) He wins and makes a positive profit if $b_{k}>$ $v_{k_{\text {max }}}>p$ and $\hat{v}_{k}>p$. Bidding within the interval value might not ensure his win. (2) He wins but makes a negative profit if $b_{k}>v_{k_{\max }}>p$ and $\hat{v}_{k}<p$, or if $b_{k}>p>v_{k_{\max }}$. Bidding within the value range would have better payoff. And, (3) he loses if $p>b_{k}>v_{k_{\max }}$. Bidding within the interval would not do any better. Therefore the strategy of bidding outside the interval value is weakly dominated by the strategy of bidding within the value range.

Bidding in point estimate within the interval value does not guarantee winning the auction with positive profit as there is an uncertainty in determining the winner's payoff. The question is where inside the range he would bid to ensure his win. By choosing a point bid anywhere within the given interval value might not ensure a win as the highest bid might be 
higher than his bid. He could bid the upper end of the interval values. But, even if he wins, it is not certain that he would make a positive profit due to the random part involved in determining the profit. i.e., $b_{k}>p$ but $\hat{v}_{k}<p$. It depends on the risk preference of the bidder. Assume bidders are risk neutral. Also, the values are selected from a uniform distribution - any range of values is equally likely to be selected. By definition, risk neutrality would induce bidders to bid the expected value. Given uniform distribution of values and risk neutrality, the bidder $k$ would select his bid where his expectation of given interval values equates the bid, $E\left[v_{k_{\min }}, v_{k_{\max }}\right]=$ $b_{k}=v_{k_{\text {median }}} \equiv v_{k_{\text {mean }}}$. To study bidders' bidding behavior, we test this hypothesis that bidders would bid the expected value.

\section{Interval Value/Interval Bid}

Bidders face a few choices when they have interval values and they bid in a range - whether to bid a point or a range; bid outside or inside the interval values; if inside, where inside the interval values. There might be several potential equilibria in this case and it is difficult to validate Nash equilibrium predictions in the lab given subjects' risk preference (Hey and Orme, 1994). To make our analysis tractable, we assume risk neutrality as a standard and analyze behavior accordingly. Given uniform distribution and risk neutrality, we predict two symmetric equilibria - (i) bidders bid expected value; and (ii) bidders bid their value interval.

Assume nature selects a range of private values $v \in\left\{v_{k_{\min }}, v_{k_{\max }}\right\}$ for each of $k$ bidders. Bidders submit their interval bids, $b \in\left\{b_{k_{\text {min }}}, b_{k_{\text {max }}}\right\}$. The highest bidder, say the $k$ th bidder, can buy the good if a random number drawn from his range of bids, $\hat{b}_{k}$, exceeds the market price. His payoff depends on two random numbers — one drawn from his interval values and the other drawn from submitted interval bids, i.e., $\hat{v}_{k}$. The payoff is, $\pi_{k}=\hat{v}_{k}-p$. The bidder will incur a positive profit if (i) $\hat{b}_{k}>p$ and (ii) $\hat{v}_{k}>p$. 
No rational bidder has any incentive to choose his interval bid entirely above or below the given interval values. Also, a bidder does not want to choose the interval bid lower than the value interval (e.g., $b_{k_{\min }}<v_{k_{\min }}$ ). By doing so, the bidder would increase the chance of losing a profitable item in the auction. However, a bidder could raise the probability of wining the auction by choosing the upper end of the interval bid little higher than the value, $b_{k_{\max }}>v_{k_{\max }}$, as he is going to pay the second highest bid if he wins.

Suppose the bidder $k$ chooses interval bid, $\left\{b_{k_{\text {min }}}, b_{k_{\max }}\right\}$, little higher than the given interval values such that $b_{k_{\max }}=v_{k_{\max }}+\varepsilon$, where $\varepsilon>0$, and $b_{k_{\min }} \geq v_{k_{\min }}$. The possible outcomes are the following. (1) The bidder cannot win the auction if $p>b_{k_{\max }}$. He could not do any better if he chooses $b_{k_{\max }}=v_{k_{\max }}$. (2) He wins and makes a positive profit if $b_{k_{\max }}>$ $v_{k_{\max }}>p$, and $\hat{b}_{k}>p$ and $\hat{v}_{k}>p$. Bidding the interval value might not secure his win. (3) He wins and makes zero profit if $b_{k_{\max }}>v_{k_{\max }}>p$, and $\hat{b}_{k}>p$ and $\hat{v}_{k}=p$. Both the strategies choosing the interval little higher than the value and choosing the upper bound of interval value would generate the same payoff. (4) He wins and makes a negative profit if $b_{k_{\max }}>p>v_{k_{\max }}$ and $\hat{b}_{k}>p$. He could get a better payoff (i.e., zero profit) by bidding the interval value. The strategy of choosing the upper bound of interval bid little higher than the upper bound of interval value is weakly dominated by the strategy of choosing $b_{k_{\max }}=v_{k_{\max }}$.

Now consider the situation when the bidder chooses the upper bound of interval bid little lower than the upper bound of interval value. Suppose the bidder $k$ chooses interval bids, $\left\{b_{k_{\text {min }}}, b_{k_{\text {max }}}\right\}$ such that $b_{k_{\max }}=v_{k_{\max }}-\varepsilon$, where $\varepsilon>0$, and $b_{k_{\min }}=v_{k_{\min }}$. (1) If the market price, $p>v_{k_{\max }}$, then the bidder cannot win the auction and his payoff is zero. He would not gain anything more even if he chooses $b_{k_{\max }}=v_{k_{\max }}$. (2) If $v_{k_{\max }}>p>b_{k_{\max }}$, he cannot win 
the good. There could be a possibility of winning the auction if he chooses $v_{k_{\max }}=b_{k_{\max }}$.

He wins and makes a positive profit if $v_{k_{\max }}>b_{k_{\max }}>p$, and $\hat{b}_{k}>p$ and $\hat{v}_{k}>p$. He could have obtained the same payoff by selecting $v_{k_{\max }}=b_{k_{\max }}$ provided that $\hat{b}_{k}>p$ and $\hat{v}_{k}>p$. Therefore, choosing $v_{k_{\max }}=b_{k_{\max }}$ weakly dominates the strategy of selecting interval such that $b_{k_{\max }}=v_{k_{\max }}-\varepsilon$, where $\varepsilon>0$, and $b_{k_{\min }}=v_{k_{\min }}$.

Bidding interval value sincerely does not guarantee winning the auction with positive profit. In our case, a new uncertainty pops in through the random components in determining the winner and the winner's payoff. By choosing an interval bid equals given interval values might not ensure a win as the random number drawn from the submitted interval bid might stay below the highest bid, i.e., $p \in\left\{b_{k_{\max }}, b_{k_{\min }}\right\}$, but $\hat{b}_{k}<p$. Also, even if he wins, it is not certain that he would make a positive profit due to the random part involved in determining the profit. A risk neutral bidder rather bid the expected value, given symmetric bidders.

Given risk neutrality and uniform distribution, we have two potential symmetric equilibria to consider: (1) point bid = expected value, and (2) bid the interval value. Any chosen interval bid such that expected bid equates expected value is a possible equilibrium. Our statistical analysis will investigate whether the bidders bid in point and then whether the point bids are expected value. To test whether bidders bid their interval values, we examine in our statistical analysis whether the expected value of given private interval values equates the expected bid of their selected interval bids. This is because the values are selected from a uniform distribution. If bidders choose interval values, the interval bids also follow a uniform distribution. Testing the hypothesis that $b_{\text {mean }}=E\left[b_{\text {min }}, b_{\text {max }}\right]=E\left[v_{\text {min }}, v_{\text {max }}\right]=v_{\text {mean }}$, we can actually test whether they choose interval bids sincerely given interval values (i.e., interval values $=$ interval bids) . 


\section{Experimental Design \& Hypotheses}

We develop a 2x2 second-price auction experiment design to create four treatments: (i) a benchmark point value/point bid, (ii) point value/interval bid, (iii) interval values/point bid, and (iv) interval values/interval bid. Seventy University of Wyoming undergraduate and graduate students participated in total seven sessions of auction. At the beginning of every session, the monitor read the instruction of the auction aloud and addressed any questions (see Appendix A in Reviewer Appendices). Bidders answered a short quiz which ensured they understood the auction. Verbal communication between bidders was prohibited. Participants received $\$ 5$ to show up.

Each treatment but the treatment one had two sessions with 10 bidders in each session. Bidders played 10 rounds in each session. Treatment one had one session with 10 bidders bidding over 10 rounds. In every session, participants played 5 practice rounds. In each round, one hypothetical good was in auction and bidders were given private values for the good. These private values were randomly drawn from a uniform distribution. They submitted their bid in a sealed envelope simultaneously and then their bids were ranked from highest to lowest. The market price, i.e., the second highest bid was announced. Highest bidder won and paid second highest bid to the experimenter who bought back the good from the highest bidder. The difference between the private value of the highest bidder and the second highest bid was his payoff. Other bidders could not win and had zero profit. In the next round different values were assigned to different bidders and again values were drawn from a uniform distribution. At the end of 10 rounds, total amount of surplus of each bidder was converted into monetary units and paid in cash. 
2.1. Point-Point Benchmark. The benchmark treatment is a standard Vickrey secondprice auction point value/point bid design (see Kagel, 1995). Following standard auction procedures, bidders were assigned a point value at the beginning of each round, and they were asked to submit their bid as point value. Following Shogren et al. (2001), a demand curve of private values we created from random draws from a uniform distribution of $[\$ 0.10, \$ 10]$ in $\$ 0.10$ increments: [\$0.40, \$1.80, \$3.20, \$5.30, \$6.10, \$6.50, \$6.80, \$7.10, \$7.60, \$8.40]. In each round, each bidder was given a new point value, and asked to submit his bid in a sealed envelope. The monitor ranked those bids from highest to lowest. The highest bidder won and paid second highest bid. The highest bidder's profit is the difference between his resale value (i.e., his induced value) and the market price (i.e., second highest bid). In theory, bidding behavior within this classic second-price auction is well-known to be weakly demand revealing (Vickrey 1961). A bidder's incentive is to bid his induced value since overbidding risks paying too much and underbidding risks missing out on a profitable opportunity (see, e.g., Milgrom and Weber 1982), which we summarize as:

Benchmark hypothesis: Given a point private value in a second-price auction, bidders asked to bid a point estimate bid their private value (Vickrey, 1961).

3.2. Point value/interval bid. We now alter our design slightly to address the question of how bidders bid if they have a point value but are asked to state a value interval, as in Hanley et al. (2009). The concern is that we might induce a new bias by asking for an interval bid from people who have well-formed preferences for the good — a point value. Each bidder was again assigned a point value [from the same set of induced values as in the benchmark treatment], but each bidder was asked to bid in an interval of values, \$a - \$z. Bidders were informed that they could submit a point bid under this treatment —-they did so by putting the same bid in the upper 
and lower bound of the interval bid, e.g., $\$ a=\$ z$; or $\$ 40-\$ 40$. Bidders also knew that winner of the auction would be determined as follows. A monitor would rank-order bids based on one randomly drawn number from each of their interval bids. Again the highest bidder won and paid the second highest bid. In theory, if a bidder is asked to submit bids in intervals given they have a point value, rational bidders have two choices: (1) bid a range or a point; and (2) bid sincerely or not. If a bidder believes the other bidders are rational, each bidder should bid a point equal to his point value, which we summarize as:

Point value/interval bid Hypothesis: Given point private value and the opportunity to bid in interval, (i) a bidder bids his true point value; and (ii) a bidder choose his expected bid corresponding to his true point value.

\subsection{Interval value/point bid. We now alter our design to address the elicitation} question of how bidders bid if they have a value interval (coherent arbitrariness) but are asked to state a point estimate, as in a classic stated preference survey. Bidders were assigned interval values, which were determined from a uniform distribution of $[\$ 0.10, \$ 10]$ : $[\{\$ 0.10, \$ 0.40\}$, $\{\$ 0.40, \$ 1.80\},\{\$ 1.80, \$ 3.20\},\{\$ 3.20, \$ 5.30\},\{\$ 5.30, \$ 6.10\},\{\$ 6.10, \$ 6.50\},\{\$ 6.50, \$ 6.80\}$, $\{\$ 6.80, \$ 7.10\},\{\$ 7.10, \$ 7.60\},\{\$ 7.60, \$ 8.40\}] .^{1}$ Given the induced value interval, each bidder submitted a point bid. Again highest bidder won, paid the second highest bid. The winner's profit was determined by comparing the second-highest price to a value drawn randomly from the winner's interval of values. Predicting rational bidding behavior is less straightforward when bidders have interval values but must bid one single value. For concreteness, assume

\footnotetext{
${ }^{1}$ As a starting point, we selected homogenous intervals taking two consecutive point values. For example: point values $\{2,3,4, \ldots .$.$\} and interval values (\{2,3\},\{3,4\}, \ldots)$. There are other ways to select the intervals worth considering in future treatments. We could have chosen the intervals in that the mean of the intervals should be the point value (i.e., $(\{1,3\},\{3,5\}, .$.$) . The downside with this alternative approach is that given interval values, bidders$ can have different parameters (and not always the mean value) in forming their bidding strategy. In that case, scale effects can arise. Also, each round is independent and our hypothesis also based on different rounds. One might also intervals with equal lengths. Again this seems worthy of future work to examine behavior of off-margin bidders.
} 
bidders are risk neutral, and values are selected from a uniform distribution - any range of values is equally likely to be selected. Given uniform distribution of values and risk neutrality, a bidder would select his bid in which his expectation of the interval values equates the bid:

Interval value/point bid Hypothesis: Given interval values, a bidder asked to bid a point estimate will bid the mean from the interval of values.

3.4. Interval/Interval. In the final treatment, each bidder submitted an interval bid given his interval values. After all interval bids were collected, the monitor randomly selected from each bidder one value and one bid from his intervals of values and bids. The selected bids were ranked from highest to lowest and the resale value was the random number drawn from the interval values. The interval demand curve was identical to the Interval value/point bid treatment. Again assuming risk neutral bidders and a uniform distribution, it is the weakly dominant strategy for rational bidders to bid his interval values (see Appendix B):

Interval/interval Hypothesis: Given interval values, if a bidder is to bid in interval, (i) he bids his interval values; and (ii) the mean of the bid interval equals the mean of the interval values.

\section{Results}

We now discuss our key results. First, in the benchmark treatment, we find evidence that bidders bid sincerely in the second-price auction. We do not reject the benchmark hypothesis that bidders bid their values in the point-point second-price auction. Table 2 shows the unconditional bidding behavior. Bidders bid private values about half the time; they underbid 30 percent and overbid in 20 percent (see Table 4). On average, bidders bid sincerely: mean bids is 5.37 and mean values is 5.31 (Table 2); $t$-statistic rejects the hypothesis that the bids and values are different (Table 5). Table 3 shows aggregate revealed demand (i.e., observed bids) and ratio of bid to induced value in percentage for each round. It indicates revealed bids are 
close to induced private values in every round - overall, the ratio of bid to value, in percentage, is $101 \%$.

Conditional regression analysis supports this conclusion. To test whether bidders bid their private induced values, we use the following regression model

$$
B_{i t}=\alpha_{i}+\beta V_{i t}+\gamma_{t}+\varepsilon_{i t}
$$

where, $B_{i t}$ and $V_{i t}$ are bidder $i$ 's bid and induced value in round $t$; $\alpha_{i}$ denotes subject-specific characteristics; $\gamma_{t}$ represents round-specific effects which captures learning effects; and $\varepsilon_{i t}$ is the error term. In a bid-value space, data points along a $45^{\circ}$ line indicate bids are demand revealing. Our two-way panel regression analysis shows the estimate of the coefficient, $\beta=1.01$ and constant, $\alpha=-0.07$ (see Table 6). We do not reject the joint hypothesis, $\alpha=0, \beta=1$ (with chi $^{2}=$ 0.62 and Prob $>$ chi $\left.^{2}=0.73\right)$. A Scatterplot with an overlay of the regression line supports this finding (see Figure 1a). Our bidders were more rational on average than some earlier experiment work that found overbidding (see Kagel's review 1995; Cherry et al. 2004).

We now examine bidding behavior to address the three open questions on bidding behavior given interval values or interval bidding or both. First, how do bidders bid if they have a point value but are asked to state an interval bid (which could be stated as a point, e.g., \$40-\$40)? Our bidders choose not to bid a point estimate — rather they constructed a bid interval; the typical bidder formed his interval bid by using the induced point value as the mean of the interval. We summarize our findings as:

Result 1 . We reject point value/interval bid hypothesis (i) that bidders bid their point values. We cannot reject hypothesis (ii) that bidders form their expected bid based on point value.

Support. Subjects were more inclined to bid in intervals (56\%, see Table 4). They bid a point value in $22.5 \%$ of bids. Table 2 shows the mean of the expected interval bids (5.89) is close from the mean of point values (5.32). Overall, the ratio of bid (mean bid) to value is $101 \%$ for 
group one and it is little higher for group two (119\%) (see Table 3). Table 5 shows how lower bound, upper bound, and mean of interval bids are related to the private point values. The mean of differences between lower bound, upper bound, and mean of interval bids and point value are $-0.48,1.64$, and 0.58 . Results from $t$-statistics reject the hypotheses that the lower bound and the mean of interval bids are different from the values. We cannot reject the hypothesis that the upper bound of intervals and the point values are different. Bidders are likely to choose the lower bound of the interval bids lower than the given values, although it is near the point value. Rather they have a tendency to choose the upper bound of bids greater than the private point values. The mean of interval bids are close to the point value.

A logit model of whether bidders choose to submit bids in one single number-shows one additional unit increase in their value decreases the probability that they report their bids in one single number by 0.02 (Table 7). ${ }^{2}$ The result is not statistically significant. Our random effect regression of expected bid on values gives the estimate of coefficient, $\beta=0.94$ and constant, $\alpha$ $=0.26$ (Table 6). ${ }^{3} \mathrm{~A}$ one unit increase in value increases the mean bid (means of interval bids) by 0.94 . We cannot reject the joint hypothesis $\alpha=0, \beta=1$ (Table 6) -this implies bidders choose expected bids sincerely given point values. Figure $1 \mathrm{~b}$ shows the fitted regression line between mean-bid and point value is almost a $45^{\circ}$ line.

Theory predicts it is dominant strategy for rational bidders to bid their point private values even if they could bid in intervals. Our result contrasts this prediction as bidders have

\footnotetext{
${ }^{2}$ A probit model of whether bidders bid exact values or not shows a negative but insignificant impact of point value on the choice of bids equals to values (Table 8, Appendix C in Reviewer Appendices) - bidders are less likely to bid their point values.

${ }^{3}$ To capture the underlying preferences in choosing bids in points and in intervals given point and interval values, we carry out the following statistical analysis: (i) Interval regression method (see Hasselblad et al. 1980; Cameron and Huppert 1989); (ii) Quantile regression(Koenker 2005); (iii) Cluster analysis (Anderberg 1973); and (iv) Latent class analysis (Skrondal and Rabe-Hesketh (2004)). Overall, results from these techniques are not different from our summary statistics and classical regression method (see, Table 9, Appendix B), and are available on request.
} 
clear preference in the lab to bid in intervals. Evidence from field experiment supports this result as in reality people prefer to express their WTP in intervals rather than in single numbers (Hanley et al. 2009). Given the opportunity of bidding in intervals, choosing the upper bound of the interval in excess of given private point value is likely based on the impression that it increases the chance of winning with no real cost to the bidder as he/she has to pay second highest bid (see Kagel et al., 1987).

Second, how do bidders bid if they have a value interval but are asked to state a point estimate? Our results suggest bidders bid their expected value from the interval.

Result 2. We cannot reject the interval value/point bid hypothesis. Given interval values, bidders choose their point bids sincerely in that they bid expected values.

Support. Table 4 shows bidders bid within the given private interval values in $67.5 \%$ of cases. The mean of bids (5.09) is close to the mean of the expected interval values (4.90) (see Table 2). The ratio of bid to value (mean value) is close to $100 \%$ (105\% and 100\% for group one and two; see Table 3). We observe how close the bids are to the mean values - in $48 \%$ of bids were within $\$ 0.05$ of mean of interval values. Bids appear to be chosen close to the mid points of the given interval values, which suggests bidders bid expected values. Table 5 shows how point bids are related to the lower bound, upper bound, and mean of interval private values. The mean of differences between (i) point bid and lower bound of value, (ii) point bid and upper bound of value, and (iii) point bid and mean value are $0.55,-0.27$, and 0.14 . This implies bids are mostly within the interval values and close to mean values. Results from $t$-statistic cannot reject the hypotheses that the lower bound and the upper bound of interval values are different from the point bids.

Again our two way random effect regression of point bids on mean of interval values shows the estimates of slope, $\beta=0.96$ and intercept, $\alpha=0.071$ (Table 6). It means one unit 
change in medians of interval values raises bids by 0.96 . The joint hypothesis of, $\alpha=0, \beta=1$, cannot be rejected (with $\operatorname{chi}^{2}=0.97$, Prob. $>\operatorname{chi}^{2}=0.61$ ) (see Figure 1C). Our model predicts, given interval values, risk neutral bidders should bid expected values. Results support this prediction. Bidders again seemed to choose their bids sincerely corresponding to the mean of interval values.

Third, how do bidders bid if they have an interval value and they state an interval bid? Our bidders bid sincerely again, as measured by equality in the expected values of the bid and value intervals.

Result 3. We reject the hypothesis that people can sincerely bid their true interval values. We cannot reject the hypothesis that the expectation of chosen bids is expected values.

Support. Table 4 shows $77 \%$ of bids are in intervals. Subjects bid exact private value range in only $4.5 \%$ of cases. The lower bound of bid range exceeds the upper bound of value range in $22 \%$ of cases and the upper bound of bid range lies below the lower bound of value range in $15 \%$ of cases. We check how lower bound, upper bound, and mean of chosen interval bids are related to the lower bound, upper bound, and mean of interval private values. However, summary statistics shows the mean of the expected interval bids (6.44) is higher than the mean of the interval values (4.90, see Table 2); this suggest overbidding. For group one (G1) bidders, we see this overbidding as the ratio of mean bid to mean value is far away from $100 \%$ (159\%) whereas it becomes 102\% for group two bidders. The mean of upper bound points of interval bids (7.43) are much higher than its counterpart (5.32) compared to the mean of lower bound of interval bids (5.46) and values (4.49). The lower end points of the interval bids are below the lower bound of interval values in $34.5 \%$ of cases and they exceed the interval values in $22 \%$ of cases. In contrast, people choose the upper bound of their interval bids higher than the interval values more frequently. The upper bound of interval bids exceed the upper bound of interval 
value in $46.5 \%$ of cases; they stay lower the lower bound of interval values in $15 \%$ of cases. Table 5 shows the means of differences between (i) lower bound of bid and lower bound value, (ii) upper bound of bid and upper bound of value, and (iii) mean of interval bid and mean of interval value are $0.97,2.12$, and 1.54 . This implies bidders overbid by choosing upper bounds of interval bids higher than the upper bounds of interval values. However, lower bounds of interval bids are close to the corresponding lower bound of interval values. Results from $t$-statistic cannot reject the hypotheses that (i) the upper bound of interval bids and upper bound of values, and (ii) mean bids and mean values are different. We reject the hypothesis that the lower bound of interval bids and values are different. It implies bidders chose interval bids in such that lower bounds of bids are close to lower bound of intervals, but upper bounds of bids are higher than its counterpart.

We now verify the unconditional results of summary statistics using conditional regression analysis. We first examine whether people prefer to bid in one single number by conducting a logit regression. A logit model of point bid on mean-value illustrates there is almost zero and insignificant impact of mean-value on point bids (Table 7). So we cannot conclude that people are likely to report their bids in one single number. The two way random effect of means of interval bids on means of interval values is performed. Result shows the estimates of slope, $\beta$ $=0.87$ and intercept, $\alpha=0.05$ (Table 6). It suggests people raise their mean-bids by 0.87 with 1 unit increase in mean-values, provided intervals are represented by the medians. The fitted line between the median s of interval bids and values has a slope of 0.87 and an intercept of 0.05 . Also, we cannot reject that the values and bids have a one-to-one relation as the joint hypothesis, $\alpha=0, \beta=1$, cannot be rejected. This result indicates bidders choose their expected bids 
sincerely given expected values ${ }^{4}$. Figure $1 \mathrm{D}$ shows a fitted regression line overlaid in a scatter plot between the mean-bid and mean-value. In spite of few outliers, the fitted line is a $45^{\circ}$ line.

Given interval values, bidders form interval bids such that upper bound bids are higher than the upper bound values. However, expected bids are expected values. They keep mean bids close to mean values and try to increase the probability of winning by selecting upper bounds bids higher than upper bound values.

In summary, result from treatment I (i.e., Point value/interval bid) shows bidders prefer to bid in interval. They form their interval such that expected bid is the point value. Given interval value and point bid (treatment II), submitted bids are equal to the expectation of interval values. Under treatment III (Interval value/interval bid), they form interval bids such that the expected bid equals expected interval value.

\section{Concluding Remarks}

The rational choice theory underlying preference elicitation methods presume people have well-formed preferences for environmental goods_-people have point estimates of their willingness to pay. Evidence exists, however, which suggests people might not be so precise; rather they could have a range or interval of values when considering non-market goods. Herein we explore bidding behavior in a second-price auction when bidders have point or interval values and point or interval bidding possibilities. Our result supports one presumption of coherent arbitrariness (Ariely et al. 2003) and the finding of Hanley et al. (2009): people seem to prefer to express their WTP in intervals - bidders report their bids in an interval rather than in a single

\footnotetext{
${ }^{4}$ As values are drawn from uniform distribution, which is a standard practice in auction literature, mean and median of the distribution coincide. Bidders might just use midpoint as reference, not the expectation of the values. We understand this limitation of our work, especially when we are exploring how bidders construct their bids given interval values. Future research would investigate this possibility by considering asymmetric distribution. We thank anonymous reviewer for pointing this out.
} 
number regardless of whether they were induced with point or interval values. Also, people behaved "rationally" in that they constructed their bids based on expected values. When the bidders had point values, they tended to submit an interval bid using their true point value as the mean of the interval. If they had interval values, bidders sincerely bid their interval values - the expected bid corresponded to the expected value.

Based on these experiments, we are not proposing to the interval bidding is better than the standard point bidding. Our goal was to understand better what happens with researchers get it "wrong" by eliciting interval values with point bidding, and visa versa. Promoting the idea of coherent arbitrariness within the field of preference elicitation will make more/less sense as we observe how people actually bid when the values and mechanisms are aligned and misaligned. We will understand our demand estimates better when we better understand the robustness of people's bidding behavior - rational and otherwise - to the institution (Smith, 2003). For now, our induced value results suggests two ideas worth further exploration in the lab and for stated preference methods: (i) allowing people to state preferences as interval did not drastically alter rational incentives, and (ii) mean of interval WTP could provide a reasonable estimate of the "true value" for a non-market good or service.

We recognize our case is a simplification_-our bidders used mean/median as reference points given values were drawn from a uniform distribution. In applying the interval method in the field, people will use a variety of internal reference points to construct their point estimates for homegrown values. Systematically accounting for heterogeneous reference points back to Peter Bohm's (1972) original “interval method” idea. Bohm (1979) argued that bid design in valuation surveys should be more pragmatic; recognizing that people probably find it a challenge to state a point estimate. If so, bid design should promote both "controlled" over- and 
underbidding in point estimates such that an "average interval" is created (see Figure 1 in Bohm, 1979). Future research that combines Bohm's original interval ideas with the new thinking on coherent arbitrariness, anchoring, and starting point biases seems worthwhile. 


\section{References}

Anderberg, M.R. ,1973. Cluster Analysis for Applications. Academic Press: New York.

Ariely, D., Lowenstein, G., Prelec, D., 2003. Coherent Arbitrariness: Stable Demand Curves Without Stable Preferences. Quarterly Journal of Economics 118, 73-105.

Bateman, I. J., Willis, K. G., (eds.) 1999. Contingent Valuation of Environmental Preferences: Assessing Theory and Practice in the USA, Europe, and Developing Countries. Oxford: Oxford University Press.

Bockstael, N and A. M. Freeman (2005), “The Theory of Environmental Valuation.” Chapter 5 in Handbook of Environmental Economics, K-G. Maler and J. Vincent (eds).

Bohm, P., 1972. Estimating Demand for Public Goods: An Experiment. European Economic Review 3, 111-130.

Bohm, P., 1979. Estimating Willingness to Pay: Why and How? Scandinavian Journal of Economics LXXXI, 142-153.

Blumenschein, K., G. C., Blomquist, M. Johannesson, N. Horn, and P. Freeman (2008), 'Eliciting Willingness to Pay Without Bias: Evidence from a Field Experiment,' Economic Journal, Vol. 118 (525), pp. 114-137.

Cameron, T. A., Huppert, D. D., 1989. OLS versus ML Estimation of Non-Market Resource Values with Payment Card Interval Data. Journal of Environmental Economics and Management 17, 230-246.

Cherry, T. L., Frykblom, P., Shogren, J. F., List, J. A., Sullivan, M. B., 2004. Laboratory testbeds and non-market valuation: The case of bidding behavior in a second-price auction with an outside option. Environmental and Resource Economics 29, 285-294. 
Ciriacy-Wantrup, S. V., 1947. Capital Returns from Soil-Conservation Practices. Journal of Farm Economics 29, 1188-90.

Flachaire, E., Hollard, G., 2007. Starting point bias and respondent uncertainty in dichotomous choice contingent valuation surveys. Resource and Energy Economics 29, 183-194.

Hanley, N., Kristrom, B., Shogren, J. F., 2009. Coherent Arbitrariness: On Value Uncertainty for Environmental Goods. Land Economics 85 (1), 41-50.

Hasselblad, V., Stead, A. G., Galke, W., 1980. Analysis of Coarsely Grouped Data from the Lognormal Distribution. Journal of the American Statistical Association 75 (372), 771-778.

Jacquemet, N., R. Joule, S. Luchini, and J. F. Shogren (2013), 'Preference elicitation under oath,' Journal of Environmental Economics and Management, Vol. 65 (1), pp. 110-132.

Kagel, J. H., Harstad, R. M., Levin, D., 1987. Information impact and allocation rules in auctions with affiliated private values: A Laboratory study. Econometrica 55 (6), 1275-1304.

Kagel, J. H., 1995. Auctions: A survey of experimental research, In: Kagel, J. H., and A. E Roth (eds), Handbook of Experimental Economics. Princeton University Press, Princeton, NJ, 501-585.

Kahneman, D., Sugden, R., 2005. Experienced Utility as a Standard Policy Evaluation. Environmental and Resource Economics 32, 161-181.

Koenker, R., 2005. Quantile Regression. Cambridge University Press.

Lusk, J. L., \& Shogren, J. F. (2007). Experimental auctions: Methods and applications in economic and marketing research. Cambridge University Press.

Manski, C. F., Molinari, F., 2010. Rounding Probabilistic Expectations in Surveys. Journal of Business and Economic Statistics 28, 219-231.

Marshall, A., 1890. Principles of Economics, $8^{\text {th }}$ Edition. London: Macmillan and Co., Ltd. 
Milgrom, P. R., Weber, R. J., 1982. A Theory of Auctions and Competitive Bidding.

Econometrica 50 (5), 1089-1122.

Plott, C. R., and Zeiler, K., (2005). The willingness to pay/willingness to accept gap, the endowment effect, subject misconceptions and experimental procedures for eliciting valuations. American Economic Review, Vol. 95 (3), pp.

Shogren, J., 2005. Experimental Methods and Valuation, In: Handbook of Environmental Economics, vol. 2, KG Maler and J. Vincent, eds. Elsevier, Amsterdam, 969-1028.

Shogren, J. F., Margolis, M., Koo, C., List, J. A., 2001. A Random nth-price Auction. Journal of Economic Behavior \& Organization 46, 409-421.

Skrondal, A., Rabe-Hesketh, S., 2004. Generalized Latent Variable Modeling: Multilevel, Longitudinal, and Structural Equation Models. Chapman \& Hall/CRC.

Smith, V. L. (2003), 'Constructivist and Ecological Rationality in Economics', American Economic Review, Vol. 93 (3), pp. 465-508.

Vickrey, W., 1961. Counterspeculation, auctions, and competitive sealed tenders. Journal of Finance 16, 8-37. 
Table 1

\begin{tabular}{|c|c|}
\hline Article & Main Findings \\
\hline Ariely et al. (2010) & $\begin{array}{l}\text { - An arbitrary hedonic anchor, annoying sound, was used to investigate } \\
\text { bidding behavior in a second price auction } \\
\text { - Subjects could use other people's bidding behavior in choosing their } \\
\text { bids. } \\
\text { - Results show interrelation between bidding behavior and others' past } \\
\text { bids even in a private value auction. }\end{array}$ \\
\hline
\end{tabular}

Chen et al. (2007)

- Bidders might not know the distribution of their private values in a first and second price auction in the lab

- Underbidding in the presence of ambiguity about private values.

Lange, List, and Price (2010)
- $\quad$ First price and English auction

- Ex ante uncertainty over private values

- Bidder's behavior linked to the existence and structure of potential resale market

- Equilibrium bidding strategies depend on option values conveyed from the secondary market

- Results from lab and field experiments support risk-averse bidding behavior compared to risk neutral behavior.

Loewenstein and Issacharoff (1994)
- Valuation of a good depends on whether it is obtained by chance or through performance - value more if it is attributed to performance

- This source dependent valuation is similar to the endowment effect people value a good more when they posses it compared to no possession.
McGee (2012)
- In a lab experiment with uncertainty over final values, $18 \%$ and $27 \%$ of bids are above the expected value of the item in private-value firstprice and English auction.

- Results do not support any impact of risk preference on overbidding.

- Some people are prone to overbidding, similar to the 'auction fever' case.
- Underbidding in $2^{\text {nd }}$ price and $1^{\text {st }}$ price auction given value uncertainty. However, this gets reduced in a $2^{\text {nd }}$ price auction 
Table 2: Mean of values and bids

\begin{tabular}{ccccc}
\hline & Treatment I & Treatment II & Treatment III & Treatment IV \\
\hline Point Value & $5.31(2.52)^{*}$ & $5.31(2.52)$ & - & - \\
Point Bid & $5.37(2.64)$ & - & $5.04(2.99)$ & - \\
& - & - & $4.49(2.72)$ & $4.49(2.72)$ \\
$\begin{array}{c}\text { Lower bound of } \\
\text { Value Range }\end{array}$ & - & - & $5.32(2.52)$ & $5.32(2.52)$ \\
$\begin{array}{c}\text { Upper bound of } \\
\text { Value Range } \\
\begin{array}{c}\text { Mean of Value } \\
\text { Range }\end{array}\end{array}$ & - & - & $4.90(2.60)$ & $4.90(2.60)$ \\
$\begin{array}{c}\text { Lower bound of } \\
\text { Bid Range }\end{array}$ & - & $4.83(4.20)$ & - & $5.46(9.41)$ \\
$\begin{array}{c}\text { Upper bound of } \\
\text { Bid Range } \\
\text { Mean of Bid } \\
\text { Range }\end{array}$ & - & $6.95(6.59)$ & - & $7.43(11.60)$ \\
\hline
\end{tabular}

*standard deviations are in parenthesis 
Table 3: Aggregate bidding behavior in each round

\begin{tabular}{|c|c|c|c|c|c|c|c|c|c|c|c|}
\hline & \multicolumn{11}{|c|}{ Round } \\
\hline & 1 & 2 & 3 & 4 & 5 & 6 & 7 & 8 & 9 & 10 & Total \\
\hline \multicolumn{12}{|c|}{ T 0} \\
\hline \multirow[t]{2}{*}{ G1 } & 53.83 & 53.99 & 53.75 & 55.6 & 53.1 & 54.05 & 53.8 & 50.39 & 56.23 & 52.94 & 537.68 \\
\hline & $\begin{array}{l}101.18 \\
\%\end{array}$ & $101.48 \%$ & $101.03 \%$ & $104.51 \%$ & $99.81 \%$ & $101.59 \%$ & $101.12 \%$ & $94.71 \%$ & $105.69 \%$ & $99.51 \%$ & $101.06 \%$ \\
\hline \multicolumn{12}{|c|}{ T I } \\
\hline \multirow[t]{2}{*}{ G1 } & 44.31 & 49.98 & 53.99 & 45.1 & 57.87 & 61.05 & 59 & 55.30 & 58.63 & 56.87 & 542.12 \\
\hline & $83.28 \%$ & $93.94 \%$ & $101.48 \%$ & $84.77 \%$ & $108.78 \%$ & $115.41 \%$ & $110.90 \%$ & 103.95\% & $110.20 \%$ & $109.79 \%$ & $101.9 \%$ \\
\hline \multirow[t]{3}{*}{ G2 } & 49.02 & 78.25 & 59.86 & 59.635 & 58.53 & 103.68 & 56.11 & 63.36 & 52.91 & 54.82 & 636.19 \\
\hline & $92.14 \%$ & $147.08 \%$ & $112.52 \%$ & $112.09 \%$ & $110.02 \%$ & $194.89 \%$ & $105.46 \%$ & $119.09 \%$ & $99.45 \%$ & $103.05 \%$ & $119.58 \%$ \\
\hline & \multicolumn{11}{|c|}{ T II } \\
\hline \multirow[t]{2}{*}{ G1 } & 69.56 & 48.45 & 47.15 & 50.36 & 48.88 & 50.61 & 49.9 & 50.45 & 50.6 & 49.7 & 515.66 \\
\hline & $\begin{array}{l}141.81 \\
\%\end{array}$ & $98.77 \%$ & $96.12 \%$ & $102.67 \%$ & $99.65 \%$ & $103.18 \%$ & $101.21 \%$ & $102.85 \%$ & $103.68 \%$ & $101.32 \%$ & $105.12 \%$ \\
\hline \multirow[t]{2}{*}{ G2 } & 51.31 & 49.2 & 47.37 & 45.35 & 46.1 & 56.1 & 49.89 & 47.7 & 50.25 & 50.4 & 493.67 \\
\hline & $\begin{array}{l}104.60 \\
\%\end{array}$ & $100.3 \%$ & $96.57 \%$ & $92.45 \%$ & $93.98 \%$ & $114.37 \%$ & $101.71 \%$ & $97.24 \%$ & $102.44 \%$ & $102.75 \%$ & $100.64 \%$ \\
\hline \multicolumn{12}{|c|}{ T III } \\
\hline \multirow[t]{2}{*}{ G1 } & 61.11 & 134.43 & 167.27 & 96.83 & 71.97 & 68 & 54.12 & 48.85 & 39.07 & 43.1 & 784.67 \\
\hline & $\begin{array}{l}124.58 \\
\%\end{array}$ & $274.06 \%$ & $341.01 \%$ & $197.41 \%$ & $146.73 \%$ & $138.63 \%$ & $110.36 \%$ & $99.56 \%$ & $79.66 \%$ & $87.68 \%$ & $159.97 \%$ \\
\hline \multirow[t]{2}{*}{ G2 } & 56.12 & 46.99 & 52.35 & 47.41 & 49.51 & 51.53 & 55.29 & 48.7 & 48.33 & 48.83 & 505.09 \\
\hline & $\begin{array}{l}114.41 \\
\%\end{array}$ & $95.81 \%$ & $106.73 \%$ & $96.65 \%$ & $100.94 \%$ & $105.06 \%$ & $112.72 \%$ & $99.28 \%$ & $98.54 \%$ & $99.56 \%$ & $102.97 \%$ \\
\hline
\end{tabular}

Note. A pair of two successive groups (G1 and G2) constitutes a Treatment and we have four Treatments (TI, T II, T III, and T IV). The upper part of each row shows the aggregate revealed demand (i.e., the observed bids) for each group in each round (in column). The bottom part reports the ratio of this revealed demand to the aggregate induced demand, in \%, in each round. The last column displays summed over rounds. 
Table 4: Overbidding, underbidding, exact bidding

$\begin{array}{llll}\text { Treatment } 0 & \text { Treatment I* } & \text { Treatment II** } & \text { Treatment III*** } \\ & & \\ \end{array}$

\begin{tabular}{|c|c|c|c|c|}
\hline Exact Point Bid & $48 \%$ & $22.5 \%$ & $67.5 \%$ & -- \\
\hline Over Bid & $22 \%$ & $20.5 \%$ & $19.5 \%$ & $22 \%$ \\
\hline Under Bid & $30 \%$ & $18.5 \%$ & $13 \%$ & $15 \%$ \\
\hline Point Bid & -- & $44 \%$ & -- & $23 \%$ \\
\hline $\begin{array}{l}\text { Exact Interval } \\
\text { Bid }\end{array}$ & -- & -- & -- & $4.5 \%$ \\
\hline $\begin{array}{l}\text { Upper bound bid } \\
\text { > Upper bound } \\
\text { value (point } \\
\text { value) }\end{array}$ & -- & $55 \%$ & -- & $46.5 \%$ \\
\hline $\begin{array}{l}\text { Lower bound bid } \\
<\text { Lower bound } \\
\text { value (point } \\
\text { value) }\end{array}$ & -- & $51 \%$ & -- & $34.5 \%$ \\
\hline \multicolumn{5}{|c|}{$\begin{array}{l}\text { *In Treatment I, Exact Point Bid implies: Upper Bound of Bid = Lower Bound of Bid = Point Value; Over Bid } \\
\text { implies: Lower Bound of Bid > Point Value; and Under Bid implies: Upper Bound of Bid < Point Value; Point Bid } \\
\text { implies: Upper Bound of Bid = Lower Bound of Bid. Note 'Exact Point Bid' is a subset of 'Point Bid'. Also note } \\
\text { 44\% point bids implies } 56 \% \text { interval bids. } \\
\text { ** In Treatment II, Exact Point Bid implies: Point Bid = Mean of Interval Value. Over Bid and Under Bid are the } \\
\text { same as in Treatment I. } \\
\text { *** In Treatment III, Over Bid implies: Lower Bound of Bid > Upper bound of Value; Under Bid implies: Upper } \\
\text { Bound of Bid L Lower bound of Value; Point Bid is number of bid submitted in point estimate; Exact Interval Bid } \\
\text { implies: Interval Value =Interval Bid. }\end{array}$} \\
\hline
\end{tabular}


Table 5: Difference between bid and value

\begin{tabular}{|c|c|c|c|c|c|c|c|c|}
\hline & & $\begin{array}{c}\text { Treatment } \\
0\end{array}$ & & $\begin{array}{c}\text { Treatment } \\
\text { I }\end{array}$ & & $\begin{array}{c}\text { Treatment } \\
\text { II }\end{array}$ & & $\begin{array}{c}\text { Treatment } \\
\text { III }\end{array}$ \\
\hline & Mean & t-statistics & Mean & t-statistics & Mean & t-statistics & Mean & t-statistics \\
\hline $\begin{array}{l}\text { Point Bid - } \\
\text { Point Value }\end{array}$ & $\begin{array}{c}0.05 \\
(0.37)^{*}\end{array}$ & 0.47 & - & - & - & - & - & - \\
\hline $\begin{array}{l}\text { Lower bound } \\
\text { Bid - Lower } \\
\text { bound Value }\end{array}$ & - & - & $\begin{array}{c}-0.48 \\
(0.273)\end{array}$ & -1.77 & $\begin{array}{c}0.55 \\
(0.217)\end{array}$ & 2.55 & $\begin{array}{c}0.97 \\
(1.02)\end{array}$ & 0.94 \\
\hline $\begin{array}{l}\text { Upper bound } \\
\text { Bid - Upper } \\
\text { bound Value }\end{array}$ & - & - & $\begin{array}{c}1.64 \\
(0.639)\end{array}$ & 2.62 & $\begin{array}{c}-0.27 \\
(0.977)\end{array}$ & -1.25 & $\begin{array}{c}2.12 \\
(1.49)\end{array}$ & 1.42 \\
\hline $\begin{array}{l}\text { Mean of bid - } \\
\text { Mean of Value }\end{array}$ & - & - & $\begin{array}{c}0.59 \\
(0.328)\end{array}$ & 1.81 & $\begin{array}{c}0.14 \\
(0.218)\end{array}$ & 0.64 & $\begin{array}{c}1.54 \\
(1.14)\end{array}$ & 1.34 \\
\hline
\end{tabular}

*standard deviations are in parenthesis 
Table 6: Two way random effect model of bid in four different treatments

\begin{tabular}{|c|c|c|c|c|}
\hline & Coefficient & Std. Error & $\mathrm{Z}$ & $\mathrm{P}>\mathrm{Z}$ \\
\hline \multicolumn{5}{|c|}{$\begin{array}{l}\text { Treatment } 0 \\
\text { (Point Bid on Point Value) }\end{array}$} \\
\hline Value* & 1.01 & 0.022 & 47.91 & 0.00 \\
\hline Constant & -0.07 & 0.131 & -0.55 & 0.583 \\
\hline \multicolumn{5}{|c|}{$\begin{array}{l}\text { Treatment I } \\
\text { (Mean Bid on Point Value) }\end{array}$} \\
\hline Value & 0.94 & 0.11 & 8.52 & 0.00 \\
\hline Constant & 0.26 & 0.67 & 0.40 & 0.691 \\
\hline \multicolumn{5}{|c|}{$\begin{array}{l}\text { Treatment II } \\
\text { (Point Bid on Mean Value) }\end{array}$} \\
\hline Value & 0.96 & 0.039 & 24.55 & 0.00 \\
\hline Constant & 0.071 & 0.357 & 0.20 & 0.843 \\
\hline \multicolumn{5}{|c|}{$\begin{array}{l}\text { Treatment III } \\
\text { (Mean Bid on Mean Value) }\end{array}$} \\
\hline Value & 0.87 & 0.223 & 3.91 & 0.000 \\
\hline Constant & 0.052 & 1.31 & 0.04 & 0.968 \\
\hline
\end{tabular}

*Note: the coefficient estimates of round in different treatments were statistically insignificant. 
Table 7: Logit Model

$\begin{array}{llll}\text { Coefficient } & \text { Std. Error } & \text { Z } & \text { P }>\text { Z }\end{array}$

\section{Treatment I}

(Whether bid point given point value)

\begin{tabular}{ccccc}
\hline Value & -0.023 & 0.108 & -0.21 & 0.830 \\
Constant & -1.82 & 1.26 & -1.44 & 0.150 \\
Treatment III & & & & \\
$\begin{array}{c}\text { (Whether bid point given value interval) } \\
\text { Value }\end{array}$ & 0.05 & 0.09 & 0.52 & 0.606 \\
\hline Constant & 2.70 & 1.51 & 1.78 & 0.074 \\
\hline
\end{tabular}


Figure 1

a. Treatment 0 (Point Value/Point Bid)

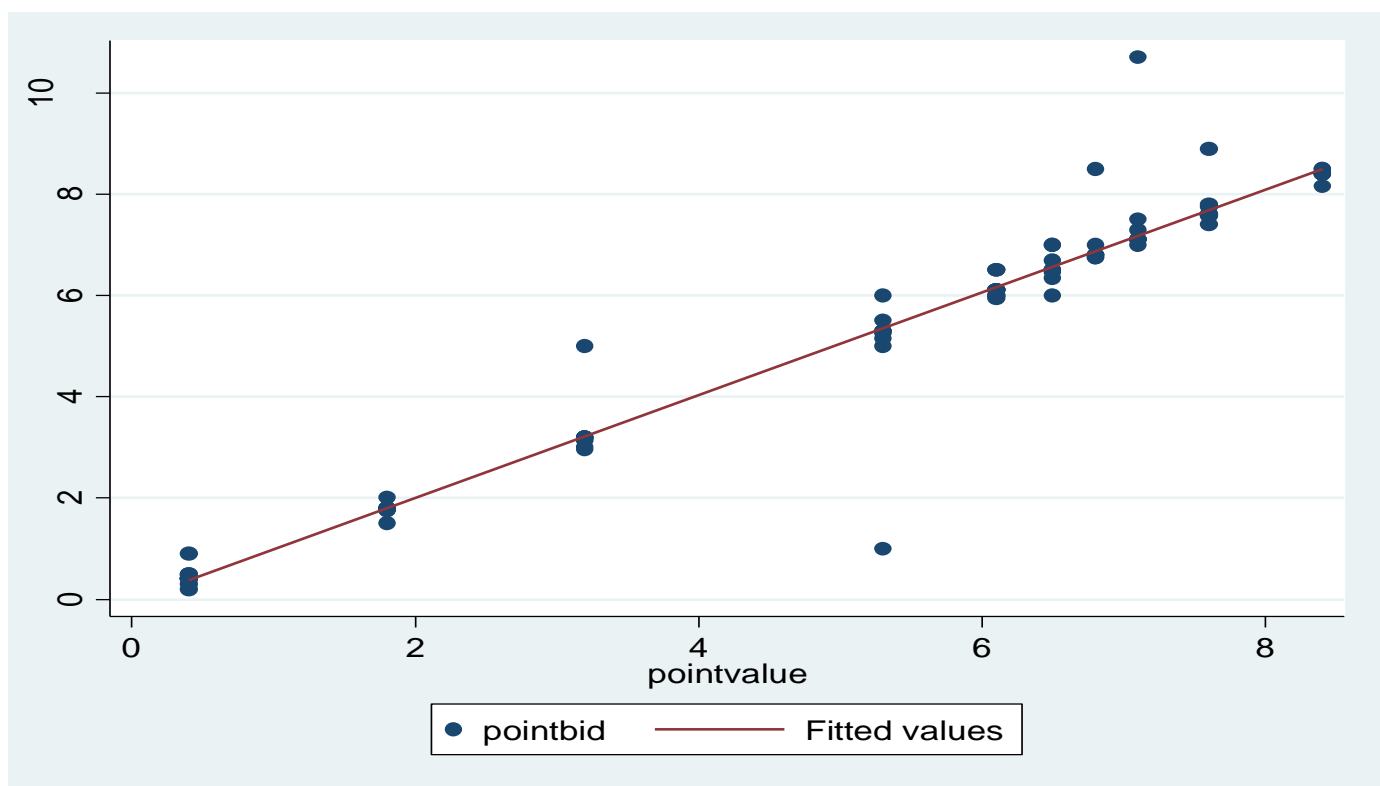

b. Treatment I (Point Value/Interval Bid)

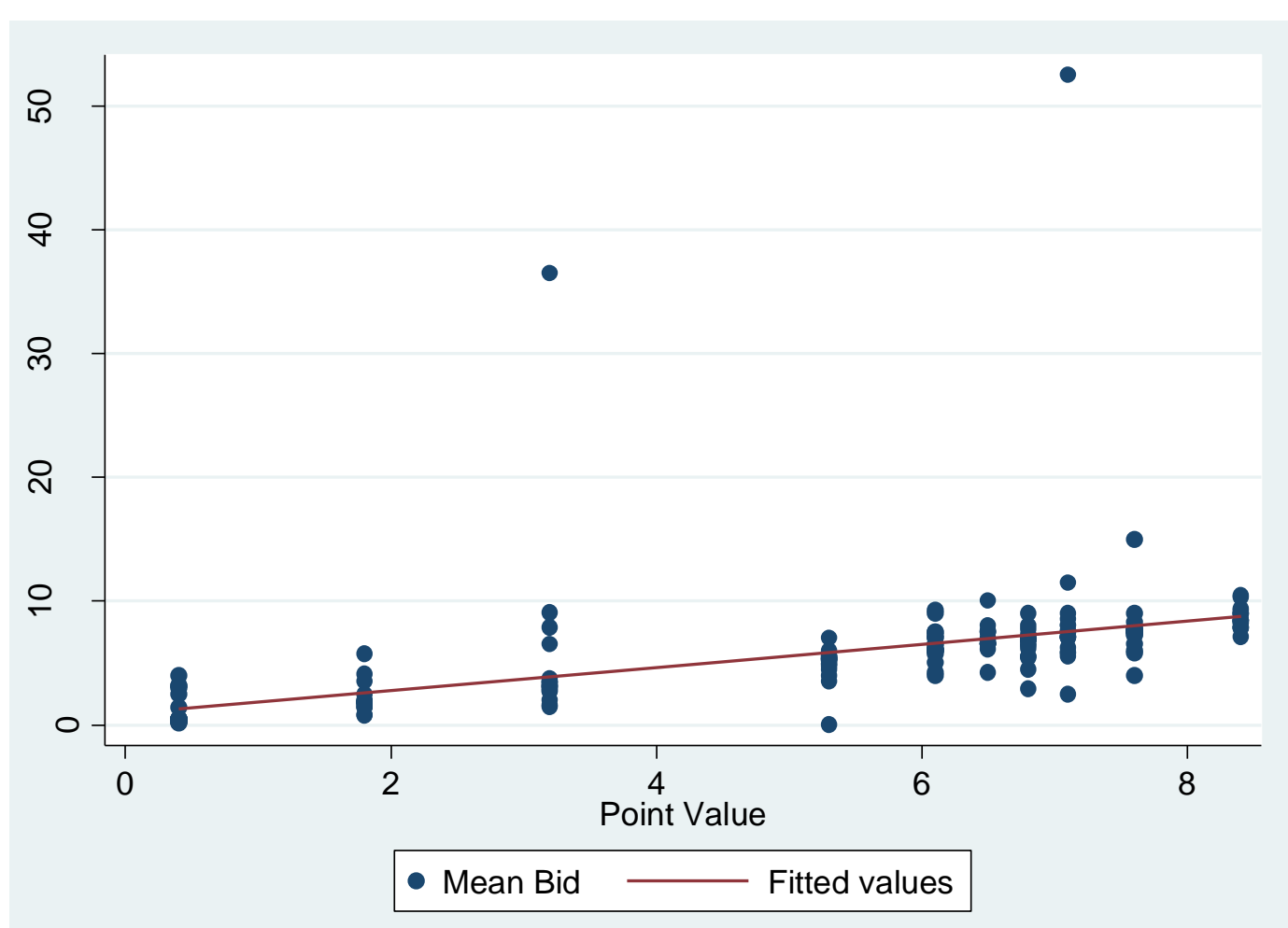


c. Treatment II (Inter Value/Point Bid)

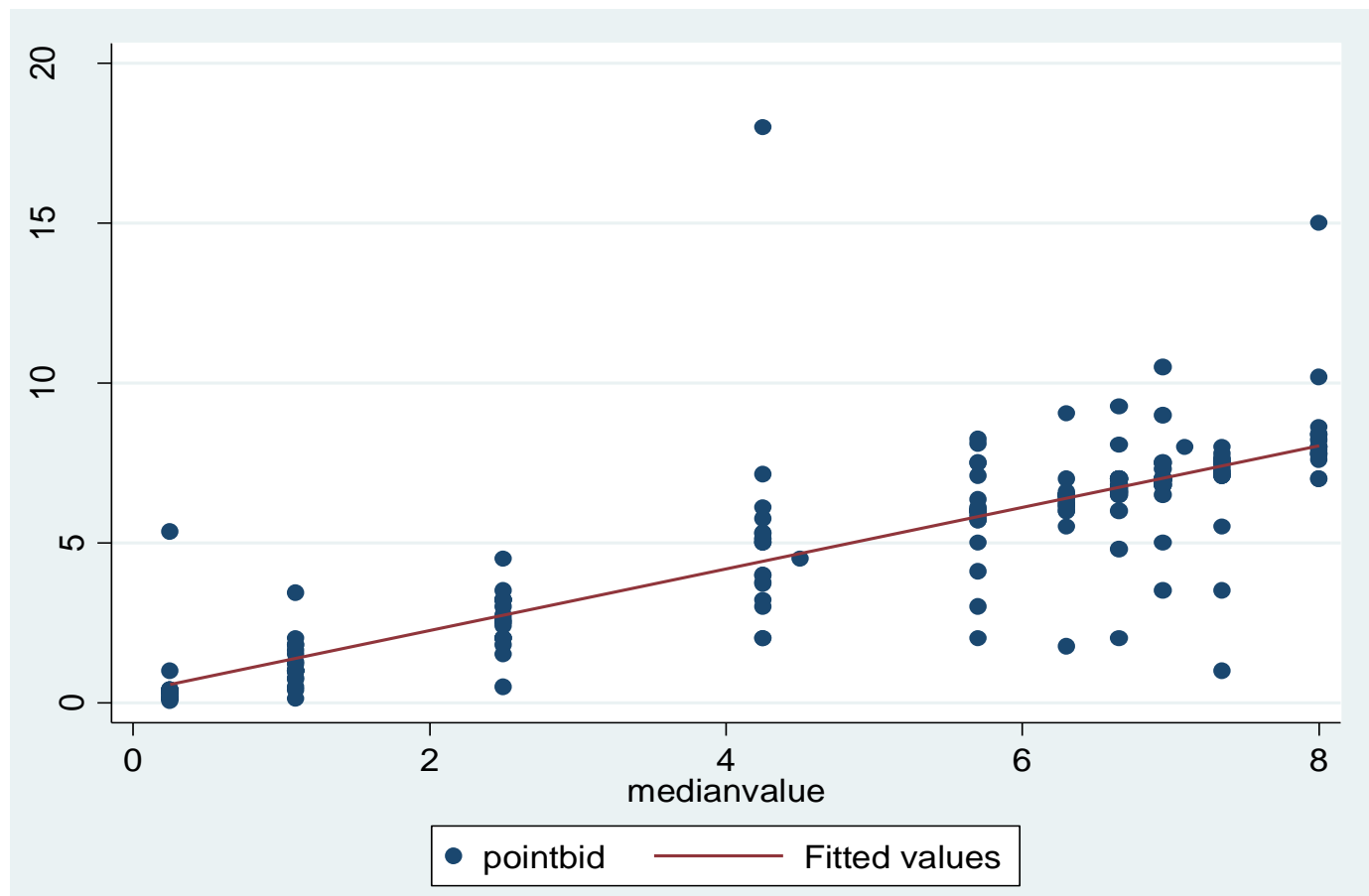

d. Treatment III (Interval Value/Interval Bid)

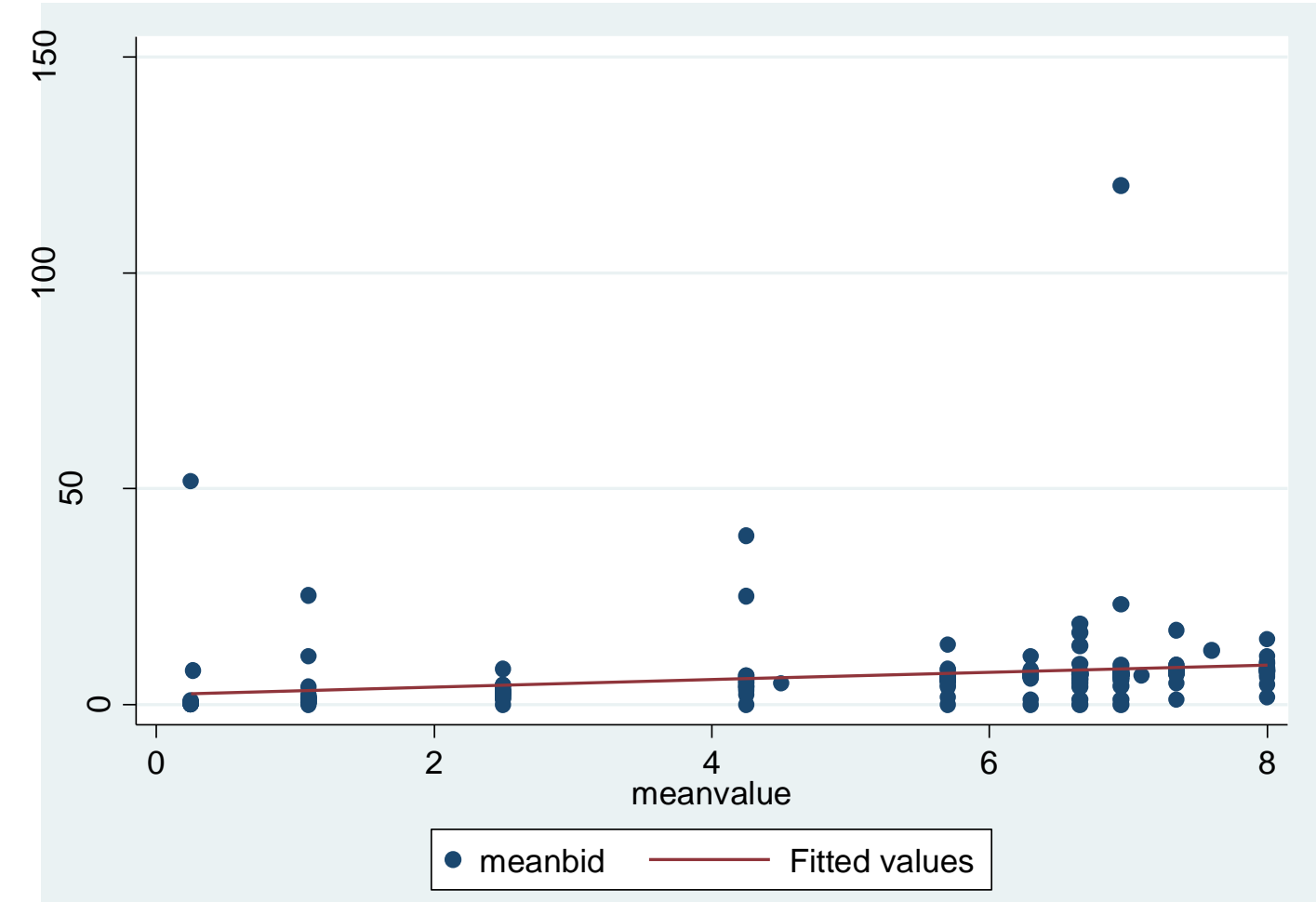




\section{Appendices}

\section{(For Reviewers' Only)}

\section{Appendix A. Experimental instructions}

\section{Instructions of the Session 1}

\section{Step 1. PRIVATE VALUE}

The monitor gives each bidder a PRIVATE VALUE on his or her recording sheet for this round. For example, you will be given a private value of \$x.xx.

\section{Step 2. POINT BID}

Each bidder then submits a POINT VALUE BID to buy one unit of the good. You submit your BID in a single value as \$a.aa.

For example, given your private value of \$x.xx, you could submit a Point Bid as \$5.25.

\section{Step 3. RANKING BIDS}

The monitor then RANKS the bids from highest to lowest:

The monitor ranks your $\$ 5.25$ bid relative to the other bidders' bids. For example, given your $\$ 5.25$ bid, you are the fourth highest bidder:

\begin{tabular}{lc}
\multicolumn{3}{l}{ Rank-ordered bids } \\
\hline Highest Bid \\
$\# 1 \quad$ \$ a.aa \\
$\# 2$ & \$ b.bb \\
$\# 3$ & \$ c.cc \\
$\# 4$ & \$ 5.25 \\
$\# 5$ & \$ e.ee \\
$\# 6$ & \$ f.ff \\
$\# 7$ & \$ g.gg \\
$\# 8$ & \$ h.hh \\
$\# 9$ & \$ i.ii \\
$\# 10$ & \$ j.jj \\
Lowest Bid \\
\hline
\end{tabular}


The market price is the bid of the second highest bidder. After bids are ranked from high to low, the second highest bid would become the market price.

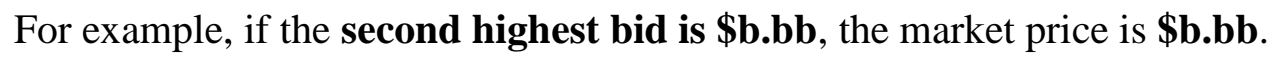

\begin{tabular}{lll}
\hline$\# 1$ & \$a.aa & \\
\hline$\# 2$ & \$b.bb & Second Highest Bid \& Market Price \\
\hline$\# 3$ & \$c.cc & \\
$\# 4$ & \$5.25 & \\
$\# 5$ & \$e.ee & \\
$\# 6$ & \$f.ff & \\
$\# 7$ & \$g.gg & \\
$\# 8$ & \$h.hh & \\
$\# 9$ & \$i.ii & \\
$\# 10$ & \$j.jj
\end{tabular}

\section{STEP5. BUYING AT THE AUCTION}

Only the highest bidder will buy one unit at the market price (i.e., bid of the second highest bidder). In our example, the highest bidder would buy one unit and would pay the second highest bid, \$b.bb.

\section{Step 6. RESALE VALUE \& PROFITS}

Resale Value: The RESALE VALUE is the price the monitor will pay a bidder to buy back a unit of a good purchased in the auction. The resale value is the private value given to you in step 1 your recording sheet.

The buyer (i.e., the highest bidder) sells the unit back to the monitor at the resale value (RV) listed for that round on your recording sheet; the difference between the resale value and the market price is the buyer's profits for that round.

$$
\text { Profits }=\text { Resale Value }- \text { market price }
$$

Suppose your private value is $\$ 6.50$, the Market Price is set at $\$ 5.00$, and you are the highest bidder. This implies you buy one unit of the good at the market price $\$ 5.00$ and sell it to the monitor at your resale value $\$ 6.50$. Your profit is positive, $\$ 1.50$ (= \$6.50 - \$5.00).

Note you can earn negative profits - if you buy a unit of the good and your RESALE VALUE is less than the Market Price, your profits are negative. Example: If your Resale value was $\$ 4.50$ and the market price was $\$ 5.00$, your profit is negative, $-\$ 0.50$ (= $\$ 4.50-\$ 5.00)$. 


\section{Step 7. BIDS BELOW MARKET PRICE}

All bidders at or below the market price do not buy anything and make zero profit for that round. Only the highest bidder can buy one unit at second highest bid value.

\section{Step 8.}

End of the round.

\section{Step 9.}

Go to the next round by going back to STEP 1, and looking at your new PRIVATE VALUE for this new round. 


\section{Example Recording Sheet}

Session 1

Person \#101

Name

\begin{tabular}{|c|c|c|c|c|c|}
\hline Round & Your Bid & $\begin{array}{l}\text { Did you } \\
\text { Buy? }\end{array}$ & $\begin{array}{c}\text { Your } \\
\text { Resale value } \\
\end{array}$ & $\begin{array}{c}\text { Market price } \\
\left(2^{\text {nd }} \text { Highest Bid }\right)\end{array}$ & $\begin{array}{c}\text { Your } \\
\text { Profits }\end{array}$ \\
\hline 1 & \$a.aa & yes & \$e.ee & \$c.cc & \$e.ee-\$c.cc \\
\hline 2 & $\$ 3.67$ & yes & $\$ 3.25$ & $\$ 3.50$ & $\begin{array}{c}-\$ 0.50 \\
(\$ 3.25-\$ 3.50)\end{array}$ \\
\hline 3 & $\$ 4.45$ & no & $\$ 4.45$ & $\$ 2.50$ & 0 \\
\hline 4 & $\$ 3.50$ & yes & $\$ 4.00$ & $\$ 1.50$ & $\begin{array}{c}\$ 2.50 \\
(\$ 4.00-\$ 1.50)\end{array}$ \\
\hline 5 & & & & & \\
\hline 6 & & & & & \\
\hline 7 & & & & & \\
\hline 8 & & & & & \\
\hline 9 & & & & & \\
\hline 10 & & & & & \\
\hline
\end{tabular}

total profits

$\$$ 


\section{Quiz 1}

Please complete the following questions.

1. Suppose your Bid is $\$ 5.00$, and you are the highest bidder. If the second highest bid is $\$ 3.00$, then you buy the unit of the good and pay
a) $\$ 3.00$
b) $\$ 5.00$
c) Whatever the monitor says

2. The market price is determined
a) By the bid of the highest bidder
b) By the price that the monitor says
c) By the bid of the second highest bidder

3. You can buy one unit of the good at this auction
a) If you are the second highest bidder
b) If the monitor selects you
c) If you are the highest bidder

4. The resale value is
a) Your private value written in the recording sheet
b) The highest bidder's value
c) Bid value of a randomly selected bidder

5. If you buy a good at $\$ 10.00$ and your resale value is $\$ 15.00$, your profit is:
a) $\$ 0.00$
b) $-\$ 5.00$
c) $\$ 5.00$ 


\section{Instructions of the Session 2}

\section{Step 1. PRIVATE VALUE}

The monitor gives each bidder a PRIVATE VALUE on his or her recording sheet for this round. For example, you will be given a private value of \$x.xx.

\section{Step 2. BID RANGE}

Each bidder then submits a BID RANGE to buy one unit of the good. You submit your Bid Range as your Minimum and Maximum bid, \{\$a.aa to $\$ b . b b\}$. Note the minimum and maximum bid can be the same number, $\{\$ a . a a$ to $\$ a . a a\}$ - this implies your bid is \$a.aa.

For example, given your private value of \$x.xx, you could submit a Bid Range as:

$\{\$ 3.01$ to $\$ 5.25\}$,

Or you could submit a bid range:

$\{\$ 3.01$ to $\$ 3.01\}$ — which implies your bid is $\$ 3.01$.

\section{Step 3. RANKING BIDS}

The monitor then RANKS the bids from highest to lowest using a two-stage process:

(i) The monitor randomly selects ONE number from your bid range. Each number in your bid range has an equal chance of being selected. For example, suppose given your bid range is $\{\$ 3.01$ to $\$ 5.25\}$, and the randomly drawn number is $\$ 3.80$. Now your bid is $\$ 3.80$ for this round of the auction.

(ii) The monitor then ranks your $\$ 3.80$ bid relative to the other bidders' bids. For example, given your $\$ 3.80$ bid, you are the fourth highest bidder:

\section{Rank-ordered bids}

\begin{tabular}{|c|c|c|}
\hline \multicolumn{3}{|c|}{ Highest Bid } \\
\hline \multicolumn{3}{|c|}{$\# 1 \quad$ \$A.AA, where \$A.AA is randomly drawn from bidder a's bid range $\{$ \$a.aa to $\$$ c.cc $\}$} \\
\hline \#2 & \$B.BB, where \$B.BB is randomly drawn from bidder b's bid range & $\{\$$ d.dd to $\$$ f.ff $\}$ \\
\hline \#3 & \$C.CC, where \$C.CC is randomly drawn from bidder c's bid range & $\{\$ g . g g$ to $\$$ i.ii $\}$ \\
\hline$\# 4$ & $\$ 3.80$, where $\$ 3.80$ is randomly drawn from your bid range & $\{\$ 3.01$ to $\$ 5.25\}$ \\
\hline$\# 5$ & \$E.EE, where $\$ \mathrm{E}$.EE is randomly drawn bidder e's from bid range & $\{\$ \mathrm{~m} . \mathrm{mm}$ to $\$ 0.00\}$ \\
\hline \#6 & $\$ F . F F$, where $\$ F . F F$ is randomly drawn from bidder f's bid range & $\{\$ p . p p$ to $\$ r . r r\}$ \\
\hline \#7 & \$G.GG, where \$G.GG is randomly drawn from bidder g's bid range & $\{\$ s . s s$ to $\$ u . u u\}$ \\
\hline$\# 8$ & $\$ \mathrm{H} . \mathrm{HH}$, where $\$ \mathrm{H} . \mathrm{HH}$ is randomly drawn from bidder h's bid range & $\{\$ v . v v$ to $\$ x . x x\}$ \\
\hline$\# 9$ & \$I.II, where \$I.II is randomly drawn from bidder i's bid range & $\{\$ y . y y$ to $\$ a . a a\}$ \\
\hline \#10 & \$J.JJ, where $\$ \mathrm{~J} . J \mathrm{~J}$ is randomly drawn from bidder j's bid range & $\{\$ \mathrm{~m} . \mathrm{mm}$ to $\$ \mathrm{t} . \mathrm{tt}\}$ \\
\hline Low & est Bid & \\
\hline
\end{tabular}




\section{STEP 4. MARKET PRICE}

The market price is the bid of the second highest bidder. After bids are ranked from high to low, the second highest bid would become the market price.

For example, if the second highest bid is $\mathbf{\$ B . B B}$, the market price is $\mathbf{\$ B . B B}$.

\begin{tabular}{lll}
\hline$\# 1$ & \$A.AA & \\
\hline$\# 2$ & \$B.BB & Second Highest Bid \& Market Price \\
\hline$\# 3$ & \$C.CC & \\
$\# 4$ & $\$ 3.80$ & \\
$\# 5$ & \$E.EE & \\
$\# 6$ & \$F.FF & \\
$\# 7$ & \$G.GG & \\
$\# 8$ & \$H.HH & \\
$\# 9$ & \$.II & \\
$\# 10$ & \$.JJ & \\
\hline
\end{tabular}

\section{STEP5. BUYING AT THE AUCTION}

Only the highest bidder will buy one unit at the market price (i.e., bid of the second highest bidder). In our example, the highest bidder would buy one unit and would pay the second highest bid, \$B.BB.

\section{Step 6. RESALE VALUE \& PROFITS}

Resale Value: The RESALE VALUE is the price the monitor will pay a bidder to buy back a unit of a good purchased in the auction. The resale value is the private value given to you in step 1 your recording sheet.

The buyer (i.e., the highest bidder) sells the unit back to the monitor at the resale value (RV) listed for that round on your recording sheet; the difference between the resale value and the market price is the bidder's profits for that round.

$$
\text { Profits }=\text { Resale Value }- \text { market price }
$$

Suppose your private value is $\$ 6.50$, the Market Price is set at $\$ 5.00$, and you are the highest bidder. This implies you buy one unit of the good at the market price $\$ 5.00$ and sell it to the monitor at your resale value $\$ 6.50$. Your profit is positive, $\$ 1.50$ (= $\$ 6.50$ - $\$ 5.00)$. 
Note you can earn negative profits - if you buy a unit of the good and your RESALE VALUE is less than the Market Price, your profits are negative. Example: If your Resale value was $\$ 4.50$ and the market price was $\$ 5.00$, your profit is negative, $-\$ 0.50(=\$ 4.50-\$ 5.00)$.

\section{Step 7. BIDS BELOW MARKET PRICE}

All bidders at or below the market price do not buy anything and make zero profit for that round. Only the highest bidder can buy one unit at second highest bid value.

\section{Step 8.}

End of the round.

\section{Step 9.}

Go to the next round by going back to STEP 1, and looking at your new PRIVATE VALUE for this new round. 


\section{Example Recording Sheet}

Session 2

Person

Name

\#202

\begin{tabular}{|c|c|c|c|c|c|}
\hline Round & $\begin{array}{c}\text { Your Bid Range } \\
\text { \& } \\
\text { Your Bid } \\
\end{array}$ & $\begin{array}{c}\text { Did you } \\
\text { Buy? }\end{array}$ & $\begin{array}{c}\text { Your } \\
\text { Resale value }\end{array}$ & $\begin{array}{c}\text { Market price } \\
\text { (Second Highest } \\
\text { Bid) }\end{array}$ & $\begin{array}{c}\text { Your } \\
\text { Profits }\end{array}$ \\
\hline 1 & $\begin{array}{c}\text { \{\$a.aa to } \$ \text { c.cc }\} \\
=\$\end{array}$ & yes & \$e.ee & \$CC.C & \$e.ee-\$C.CC \\
\hline 2 & $\begin{array}{c}\{\$ 2.49 \text { to } \$ 3.67\} \\
=\$\end{array}$ & yes & $\$ 3.75$ & $\$ 4.50$ & $\begin{array}{c}-\$ 0.75 \\
(\$ 3.75-\$ 4.50)\end{array}$ \\
\hline 3 & $\begin{array}{c}\{\$ 4.45 \text { to } \$ 5.10\} \\
=\$\end{array}$ & no & $\$ 4.45$ & $\$ 2.50$ & 0 \\
\hline 4 & $\begin{array}{c}\{\$ 2.50 \text { to } \$ 3.50\} \\
=\$\end{array}$ & yes & $\$ 4.00$ & $\$ 1.50$ & $\begin{array}{c}\$ 2.50 \\
(\$ 4.00-\$ 1.50)\end{array}$ \\
\hline 5 & & & & & \\
\hline 6 & & & & & \\
\hline 7 & & & & & \\
\hline 8 & & & & & \\
\hline 9 & & & & & \\
\hline 10 & & & & & \\
\hline
\end{tabular}

total profits

$\$$ 


\section{Quiz 2}

Please complete the following questions.

6. Suppose your Bid Range is $\$ 3.50$ to $\$ 5.00$, and $\$ 4.25$ is drawn randomly from this range to be your Bid. If the second highest bid is $\$ 3.00$ and you are the highest bidder, then you buy the unit of the good and pay
d) $\$ 3.00$
e) $\$ 4.25$
f) Whatever the monitor says

7. Your bid for an auction round is determined by:
a) Any number from the entire range of values
b) Your private value
c) The number randomly selected from your Bid Range

8. The market price is determined
d) By the bid of the highest bidder
e) By the bid of the second highest bidder
f) By the private value of the highest bidder

9. The resale value is

d) Your private value written in the recording sheet

e) The highest bidder's value

f) A number randomly selected from your range of bid values

10. If you buy a good at $\$ 10.00$ and your resale value is $\$ 15.00$, your profit is:
d) $\$ 0.00$
e) $-\$ 5.00$
f) $\$ 5.00$ 


\section{Instructions of the Session 3}

\section{Step 1. RANGE OF PRIVATE VALUES}

The monitor gives each bidder A RANGE PRIVATE VALUE on his or her recording sheet for this round. For example, you will be given a range - Minimum and Maximum private values $-\{\$ \mathrm{x} . \mathrm{xx}$ to \$y.yy\}.

\section{Step 2. POINT BID}

Each bidder then submits a POINT VALUE BID to buy one unit of the good. You submit your BID in a single value as \$a.aa.

For example, given your range of private values of $\{\$ x . x x$ to $\$ y \cdot y y\}$, you could submit a Point Bid as $\$ 5.25$.

\section{Step 3. RANKING BIDS}

The monitor then RANKS the bids from highest to lowest:

The monitor ranks your $\$ 5.25$ bid relative to the other bidders' bids. For example, given your $\$ 5.25$ bid, you are the fourth highest bidder:

\section{Rank-ordered bids}

\begin{tabular}{ll}
\hline \multicolumn{2}{l}{ Highest Bid } \\
$\# 1$ & \$ a.aa \\
$\# 2$ & \$ b.bb \\
$\# 3$ & \$ c.cc \\
$\# 4$ & \$ 5.25 \\
$\# 5$ & \$ e.ee \\
$\# 6$ & \$ f.ff \\
$\# 7$ & \$ g.gg \\
$\# 8$ & \$ h.hh \\
$\# 9$ & \$ i.ii \\
$\# 10$ & \$ j.jj
\end{tabular}

\section{Lowest Bid}




\section{STEP 4. MARKET PRICE}

The market price is the bid of the second highest bidder. After bids are ranked from high to low, the second highest bid would become the market price.

For example, if the second highest bid is $\$ \mathbf{b} . \mathbf{b b} \mathbf{b}$, the market price is $\$ \mathbf{b} . \mathbf{b b}$.

\begin{tabular}{lll}
\hline$\# 1$ & \$a.aa & \\
\hline$\# 2$ & \$b.bb & Second Highest Bid \& Market Price \\
\hline$\# 3$ & \$c.cc & \\
$\# 4$ & \$5.25 & \\
$\# 5$ & \$e.ee & \\
$\# 6$ & \$f.ff \\
$\# 7$ & \$g.gg \\
$\# 8$ & \$h.hh \\
$\# 9$ & \$i.ii \\
$\# 10$ & \$j.jj \\
\hline
\end{tabular}

\section{STEP5. BUYING AT THE AUCTION}

Only the highest bidder will buy one unit at the market price (i.e., bid of the second highest bidder). In our example, the highest bidder would buy one unit and would pay the second highest bid, \$b.bb.

\section{Step 6. RESALE VALUE \& PROFITS}

Resale Value: The RESALE VALUE is the price the monitor will pay a bidder to buy back a unit of a good purchased in the auction. The monitor will decide the resale value from the range of private values given to you in your recording sheet (in step 1):

The monitor randomly selects ONE number from your range of private values. Each number in your range of private values has an equal chance of being selected. For example, suppose given your range of private values is $\{\$ 3.01$ to $\$ 6.25\}$, and the randomly drawn number is $\$ 5.80$. Now your resale value is $\$ 5.80$ for this round of the auction.

The buyer (the highest bidder) sells the unit back to the monitor at the resale value (RV); the difference between the resale value and the market price is the bidder's profits for that round.

$$
\text { Profits }=\text { Resale Value }- \text { market price }
$$


Suppose your resale value is $\$ 5.80$, the Market Price is set at $\$ 5.00$, and you are the highest bidder. This implies you buy one unit of the good at the market price $\$ 5.00$ and sell it to the monitor at your resale value $\$ 5.80$. Your profit is positive, $\$ 0.80(=\$ 5.80-\$ 5.00)$.

Note you can earn negative profits - if you buy a unit of the good and your RESALE VALUE is less than the Market Price, your profits are negative. Example: If your Resale value was $\$ 4.50$ and the market price was $\$ 5.00$, your profit is negative, $-\$ 0.50$ (=\$4.50 - \$5.00).

\section{Step 7. BIDS BELOW MARKET PRICE}

All bidders at or below the market price do not buy anything and make zero profit for that round. Only the highest bidder buys one unit of the good.

\section{Step 8.}

End of the round.

\section{Step 9.}

Go to the next round by going back to STEP 1, and looking at your new PRIVATE VALUE for this new round. 


\section{Example Recording Sheet}

Session 3

Person

Name

\#303

\begin{tabular}{|c|c|c|c|c|c|}
\hline Round & Your Bid & $\begin{array}{l}\text { Did you } \\
\text { Buy? }\end{array}$ & $\begin{array}{c}\text { Your Range of } \\
\text { Private Values } \\
\text { \& } \\
\text { Resale value } \\
\end{array}$ & $\begin{array}{c}\text { Market price } \\
\text { (Second Highest } \\
\text { Bid) }\end{array}$ & $\begin{array}{c}\text { Your } \\
\text { Profits }\end{array}$ \\
\hline 1 & $\$ \mathbf{X x . x x}$ & yes & $\begin{array}{c}\{\$ a . a a \text { to } \$ \text { c.cc }\} \\
\quad=\$ \text { e.ee }\end{array}$ & \$c.cc & \$e.ee-\$c.cc \\
\hline 2 & \$k.kk & yes & $\begin{array}{c}\{\$ 2.49 \text { to } \$ 4.95\} \\
\quad=\$ \mathbf{3 . 7 5}\end{array}$ & $\$ 4.50$ & $\begin{array}{c}-\$ 0.75 \\
(\$ 3.75-\$ 4.50)\end{array}$ \\
\hline 3 & $\$ \mathrm{~m} . \mathrm{mm}$ & no & $\begin{array}{c}\{\$ 4.45 \text { to } \$ 5.10\} \\
\quad=\$ \mathbf{4 . 4 5}\end{array}$ & $\$ 2.50$ & 0 \\
\hline 4 & $\$ 3.95$ & yes & $\begin{array}{l}\{\$ 2.50 \text { to } \$ 4.50\} \\
\quad=\$ \mathbf{4 . 0 0}\end{array}$ & $\$ 1.50$ & $\begin{array}{c}\$ 2.50 \\
(\$ 4.00-\$ 1.50)\end{array}$ \\
\hline 5 & & & & & \\
\hline 6 & & & & & \\
\hline 7 & & & & & \\
\hline 8 & & & & & \\
\hline 9 & & & & & \\
\hline 10 & & & & & \\
\hline
\end{tabular}

total profits

$\$$ 


\section{Quiz 3}

Please complete the following questions.

11. Suppose your Bid is $\$ 5.00$ you are the highest bidder. If the second highest bid is $\$ 4.50$, then you buy the unit of the good and pay
a) $\$ 5.00$
b) $\$ 4.50$
c) The number drawn randomly from your range of private values

12. The resale value for this auction round is determined by:

d) Any number from the entire range of private values

e) Your bid value

f) Whatever the monitor says

13. The market price is determined

g) By the bid of the highest bidder

h) By the bid of the second highest bidder

i) By the private value of the second highest bidder

14. Suppose your Range of Private Values is $\$ 3.50$ to $\$ 5.00$, and $\$ 4.25$ is drawn randomly from this range to be the resale value. Your bid is $\$ 4.50$ and you are the highest bidder. If the market price is $\$ 3.00$, then you sell the unit of the good to the monitor at the price of
g) $\$ 3.00$
h) $\$ 4.25$
i) $\$ 4.50$

15. Suppose a random number drawn from your range of private values is $\$ 5.00$. If your bid is $\$ 7.00$ and the market price is $\$ 2.50$, then your profit is
j) $\$ 2.00$
k) $\$ 2.50$
l) $-\$ 2.50$ 


\section{Instructions of the Session 4}

\section{Step 1. RANGE OF PRIVATE VALUES}

The monitor gives each bidder A RANGE PRIVATE VALUE on his or her recording sheet for this round. For example, you will be given a range - Minimum and Maximum private values $-\{\$ \mathrm{X} . \mathrm{Xx}$ to \$y.yy\}.

\section{Step 2. BID RANGE}

Each bidder then submits a BID RANGE to buy one unit of the good. You submit your Bid Range as your Minimum and Maximum bid, \{\$a.aa to $\$ b . b b\}$. Note the minimum and maximum bid can be the same number, $\{\$ a$.aa to $\$ a . a a\}$ — this implies your bid is $\$$ a.aa.

For example, given your private value of $\{\$ x . x x$ to $\$ y . y y\}$, you could submit a Bid Range as:

$\{\$ 3.01$ to $\$ 5.25\}$,

Or you could submit a bid range:

$\{\$ 3.01$ to $\$ 3.01\}$ — which implies your bid is $\$ 3.01$.

\section{Step 3. RANKING BIDS}

The monitor then RANKS the bids from highest to lowest using a two-stage process:

(i) The monitor randomly selects ONE number from your bid range. Each number in your bid range has an equal chance of being selected. For example, suppose given your bid range is $\{\$ 3.01$ to $\$ 5.25\}$, and the randomly drawn number is $\$ 3.80$. Now your bid is $\$ 3.80$ for this round of the auction.

(ii) The monitor then ranks your $\$ 3.80$ bid relative to the other bidders' bids. For example, given your $\$ 3.80$ bid, you are the fourth highest bidder:

\section{Rank-ordered bids}

\begin{tabular}{|c|c|c|}
\hline \multicolumn{3}{|c|}{ Highest Bid } \\
\hline$\# 1$ & \$A.AA, where $\$$ A.AA is randomly drawn from bidder a's bid range & $\{\$ a . a a$ to $\$ c . c c\}$ \\
\hline$\# 2$ & \$B.BB, where \$B.BB is randomly drawn from bidder b's bid range & $\{\$ d . d d$ to $\$$ f.ff $\}$ \\
\hline$\# 3$ & \$C.CC, where \$C.CC is randomly drawn from bidder c's bid range & $\{\$ g . g g$ to $\$ \mathrm{i} . \mathrm{ii}\}$ \\
\hline \#4 & $\$ 3.80$, where $\$ 3.80$ is randomly drawn from your bid range & $\{\$ 3.01$ to $\$ 5.25\}$ \\
\hline \#5 & \$E.EE, where $\$ \mathrm{E}$.EE is randomly drawn bidder e's from bid range & $\{\$ \mathrm{~m} . \mathrm{mm}$ to $\$ 0.00\}$ \\
\hline \#6 & \$F.FF, where $\$ F . F F$ is randomly drawn from bidder f's bid range & $\{\$ p . p p$ to $\$ r . r r\}$ \\
\hline$\# 7$ & \$G.GG, where \$G.GG is randomly drawn from bidder g's bid range & $\{\$ s . s s$ to $\$$ u.uu $\}$ \\
\hline \#8 & $\$ \mathrm{H} . \mathrm{HH}$, where $\$ \mathrm{H} . \mathrm{HH}$ is randomly drawn from bidder h's bid range & $\{\$ \mathrm{~V} . \mathrm{vV}$ to $\$ \mathrm{x} . \mathrm{xx}\}$ \\
\hline \#9 & \$I.II, where \$I.II is randomly drawn from bidder i's bid range & $\{\$ y \cdot y y$ to $\$ a . a a\}$ \\
\hline \#10 & \$J.JJ, where $\$$ J.JJ is randomly drawn from bidder j's bid range & $\{\$ \mathrm{~m} . \mathrm{mm}$ to $\$ \mathrm{t} . \mathrm{tt}\}$ \\
\hline Low & est Bid & \\
\hline
\end{tabular}




\section{STEP 4. MARKET PRICE}

The market price is the bid of the second highest bidder. After bids are ranked from high to low, the second highest bid would become the market price.

For example, if the second highest bid is $\mathbf{\$ B . B B}$, the market price is $\mathbf{\$ B} . \mathbf{B B}$.

\begin{tabular}{lll}
\hline$\# 1$ & \$A.AA & \\
\hline$\# 2$ & \$B.BB & Second Highest Bid \& Market Price \\
\hline$\# 3$ & \$C.CC \\
$\# 4$ & \$3.80 \\
$\# 5$ & \$E.EE & \\
$\# 6$ & \$F.FF \\
$\# 7$ & \$G.GG \\
$\# 8$ & \$H.HH \\
$\# 9$ & \$I.II \\
$\# 10$ & \$J.JJ \\
\hline
\end{tabular}

\section{STEP5. BUYING AT THE AUCTION}

Only the highest bidder will buy one unit at the market price (i.e., bid of the second highest bidder). In our example, the highest bidder would buy one unit and would pay the second highest bid, \$B.BB.

\section{Step 6. RESALE VALUE \& PROFITS}

Resale Value: The RESALE VALUE is the price the monitor will pay a bidder to buy back a unit of a good purchased in the auction. The monitor will decide the resale value from the range of private values given to you in your recording sheet (in step 1):

The monitor randomly selects ONE number from your range of private values. Each number in your range of private values has an equal chance of being selected. For example, suppose given your range of private values is $\{\$ 3.01$ to $\$ 6.25\}$, and the randomly drawn number is $\$ 5.80$. Now your resale value is $\$ 5.80$ for this round of the auction.

The buyer (the highest bidder) sells the unit back to the monitor at the resale value (RV); the difference between the resale value and the market price is the bidder's profits for that round.

$$
\text { Profits }=\text { Resale Value }- \text { market price }
$$

Suppose your resale value is $\$ 5.80$, the Market Price (i.e., second highest bid) is set at $\$ 5.00$, and your bid is the highest bid. This implies you buy one unit of the good at the market price $\$ 5.00$ 
and sell it to the monitor at your resale value $\$ 5.80$. Your profit is positive, $\$ 0.80$ (= $\$ 5.80$ \$5.00).

Note you can earn negative profits - if you buy a unit of the good and your RESALE VALUE is less than the Market Price, your profits are negative. Example: If your Resale value was $\$ 4.50$ and the market price was $\$ 5.00$, your profit is negative, $-\$ 0.50$ (= $\$ 4.50-\$ 5.00)$.

\section{Step 7. BIDS BELOW MARKET PRICE}

All bidders at or below the market price do not buy anything and make zero profit for that round. Only the highest bidder buys one unit of good.

\section{Step 8.}

End of the round.

\section{Step 9.}

Go to the next round by going back to STEP 1, and looking at your new PRIVATE VALUE for this new round. 


\section{Example Recording Sheet}

Session 4

Person

Name

\#404

\begin{tabular}{|c|c|c|c|c|c|}
\hline Round & $\begin{array}{c}\text { Your Bid Range } \\
\& \\
\text { Your Bid }\end{array}$ & $\begin{array}{l}\text { Did you } \\
\text { Buy? }\end{array}$ & $\begin{array}{c}\text { Your Range of } \\
\text { Private Values } \\
\text { \& } \\
\text { Resale value } \\
\end{array}$ & $\begin{array}{c}\text { Market Price } \\
\text { (Second Highest } \\
\text { Bid) }\end{array}$ & $\begin{array}{l}\text { Your } \\
\text { Profits }\end{array}$ \\
\hline 1 & $\begin{array}{c}\{\$ a . a a \text { to } \$ \text { c.cc }\} \\
=\$\end{array}$ & yes & $\begin{array}{l}\{\$ \text { a.aa to } \$ \text { c.cc }\} \\
\quad=\$ Z . Z Z\end{array}$ & \$c.cc & \$Z.ZZ-\$c.cc \\
\hline 2 & $\begin{array}{c}\{\$ 2.49 \text { to } \$ 3.67\} \\
=\$\end{array}$ & yes & $\begin{array}{c}\{\$ 2.49 \text { to } \$ 4.95\} \\
\quad=\$ \mathbf{3 . 7 5}\end{array}$ & $\$ 4.50$ & $\begin{array}{c}-\$ 0.75 \\
(\$ 3.75-\$ 4.50)\end{array}$ \\
\hline 3 & $\begin{array}{c}\{\$ 4.45 \text { to } \$ 5.10\} \\
=\$\end{array}$ & no & $\begin{array}{c}\{\$ 4.45 \text { to } \$ 5.10\} \\
\quad=\$ \mathbf{4 . 4 5}\end{array}$ & $\$ 2.50$ & 0 \\
\hline 4 & $\begin{array}{c}\{\$ 2.50 \text { to } \$ 3.50\} \\
=\$\end{array}$ & yes & $\begin{array}{c}\{\$ 2.50 \text { to } \$ 4.50\} \\
\quad=\$ \mathbf{4 . 0 0}\end{array}$ & $\$ 1.50$ & $\begin{array}{c}\$ 2.50 \\
(\$ 4.00-\$ 1.50)\end{array}$ \\
\hline 5 & & & & & \\
\hline 6 & & & & & \\
\hline 7 & & & & & \\
\hline 8 & & & & & \\
\hline 9 & & & & & \\
\hline 10 & & & & & \\
\hline
\end{tabular}

total profits

$\$$ 


\section{Quiz 4}

Please complete the following questions.

16. Suppose your Bid Range is $\$ 3.50$ to $\$ 5.00$, and $\$ 4.25$ is drawn randomly from this range to be your Bid. If the second highest bid is $\$ 3.00$ and your bid is the highest, then you buy the unit of the good and pay
m) $\$ 3.00$
n) $\$ 4.25$
o) Whatever the monitor says

17. The resale value for this auction round is determined by:

g) Any number from the entire range of private values

h) Your bid value

i) Whatever the monitor says

18. The market price is determined

j) By the bid of the highest bidder

k) By the bid of the second highest bidder

l) By the private value of the highest bidder

19. Suppose your Range of Private Values is $\$ 3.50$ to $\$ 5.00$, and $\$ 4.25$ is drawn randomly from this range to be the resale value. Your bid is $\$ 4.50$. If the market price is $\$ 3.00$, then you sell the unit of the good to the monitor at the price of
p) $\$ 3.00$
q) $\$ 4.25$
r) $\$ 4.50$

20. Suppose a random number drawn from your range of private values is $\$ 5.00$. If your bid is $\$ 7.00$ and the market price is $\$ 2.50$, then your profit is
s) $\$ 2.00$
t) $\$ 2.50$
u) $-\$ 2.50$ 


\section{Appendix D. (for reviewers only)}

Table 8: Probit Model: Exact Bid = Cons + Point Value + Round + Individual + Error

\begin{tabular}{ccccc}
\hline & Coefficient & Std. Error & $\mathrm{z}$ & $\mathrm{P}>\mathrm{z}$ \\
\hline Value & -0.114 & 0.071 & -1.60 & 0.110 \\
Constant & -7.05 & 83366.42 & -0.00 & 0.999 \\
& & & & \\
\hline
\end{tabular}


Table 9. Summary of regression results of four cases under different methods

\begin{tabular}{|c|c|c|c|c|}
\hline & OLS & Interval & Quantile & Latent Class \\
\hline \multirow[t]{4}{*}{ Case I } & $\alpha=-0.07 \beta=1.01 *$ & 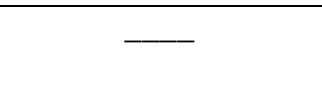 & $\begin{array}{c}\alpha=-0.14, \beta=1 * \\
\mathrm{Q}=0.25\end{array}$ & \multirow[t]{3}{*}{$\alpha=4.57 \beta=1.21$} \\
\hline & & & $\begin{array}{c}\alpha=-0.1, \beta=1 * \\
\mathrm{Q}=0.50\end{array}$ & \\
\hline & & & $\begin{array}{c}\alpha=-.05, \beta=1 * \\
\mathrm{Q}=0.75\end{array}$ & \\
\hline & $\begin{array}{c}\text { Joint Hypothesis - Not } \\
\text { Rejected }\end{array}$ & $\begin{array}{c}\text { Joint Hypothesis - } \\
\text { Not Rejected }\end{array}$ & $\begin{array}{l}\text { Joint Hypothesis - } \\
\text { Not Rejected }\end{array}$ & $\begin{array}{c}\text { Joint Hypothesis - } \\
\text { Rejected }\end{array}$ \\
\hline \multirow[t]{4}{*}{ Case II } & $\alpha=0.26 \beta=0.94 *$ & $\alpha=3.44 * \beta=1 *$ & $\begin{array}{c}\alpha=1.09 \beta=0.96 * \\
\mathrm{Q}=0.25\end{array}$ & \multirow[t]{3}{*}{$\alpha=0.09 \beta=0.99 *$} \\
\hline & & & $\begin{array}{c}\alpha=1.02 \beta=0.99 * \\
\mathrm{Q}=0.50\end{array}$ & \\
\hline & & & $\begin{array}{c}\alpha=1.61 \beta=0.98 * \\
\mathrm{Q}=0.75\end{array}$ & \\
\hline & $\begin{array}{c}\text { Joint Hypothesis - Not } \\
\text { Rejected }\end{array}$ & $\begin{array}{c}\text { Joint Hypothesis - } \\
\text { Rejected }\end{array}$ & $\begin{array}{c}\text { Joint Hypothesis - } \\
\text { Not Rejected } \\
\end{array}$ & $\begin{array}{c}\text { Joint Hypothesis - Not } \\
\text { Rejected }\end{array}$ \\
\hline \multirow[t]{4}{*}{ Case III } & $\alpha=0.07 \beta=0.96 *$ & - & $\begin{array}{c}\alpha=-0.38 \beta=1 * \\
\mathrm{Q}=0.25\end{array}$ & \multirow[t]{3}{*}{$\alpha=0.27 \beta=0.98 *$} \\
\hline & & & $\begin{array}{c}\alpha=0.23 \beta=0.99 * \\
\mathrm{Q}=0.50\end{array}$ & \\
\hline & & & $\begin{array}{c}\alpha=0.64 \beta=0.97 * \\
\mathrm{Q}=0.75\end{array}$ & \\
\hline & $\begin{array}{c}\text { Joint Hypothesis - Not } \\
\text { Rejected }\end{array}$ & $\begin{array}{l}\text { Joint Hypothesis - } \\
\text { Not Rejected }\end{array}$ & $\begin{array}{c}\text { Joint Hypothesis - } \\
\text { Not Rejected }\end{array}$ & $\begin{array}{c}\text { Joint Hypothesis - Not } \\
\text { Rejected }\end{array}$ \\
\hline \multirow[t]{4}{*}{ Case IV } & $\alpha=0.05 \beta=0.87 *$ & $\alpha=0.48 \beta=0.91 *$ & $\begin{array}{c}\alpha=0.26 \beta=0.98 * \\
\mathrm{Q}=0.25\end{array}$ & \multirow[t]{3}{*}{$\alpha=2.14 \beta=0.87 *$} \\
\hline & & & $\begin{array}{c}\alpha=0.53 \beta=1 * \\
\mathrm{Q}=0.50\end{array}$ & \\
\hline & & & $\begin{array}{c}\alpha=0.65 \beta=0.99 * \\
\mathrm{Q}=0.75\end{array}$ & \\
\hline & $\begin{array}{c}\text { Joint Hypothesis - Not } \\
\text { Rejected }\end{array}$ & $\begin{array}{c}\text { Joint Hypothesis - } \\
\text { Not Rejected }\end{array}$ & $\begin{array}{c}\text { Joint Hypothesis - } \\
\text { Not Rejected } \\
\end{array}$ & $\begin{array}{c}\text { Joint Hypothesis - } \\
\text { Rejected }\end{array}$ \\
\hline
\end{tabular}

Note: Interval regression estimates the unobserved parameter lies within the chosen interval given values using maximum likelihood technique (Cameron and Huppert 1989). Quatile regression estimates relationships between variables based on range of quantiles along with conditional distribution (Koenker 2003). Cluster analysis could capture the unobserved attitudinal preference of bidders in selecting their bids (Anderberg 1973). Latent class analysis (Rabe-Hesketh et al. 2005) characterizes unobserved subgroups of chosen interval-bids and point-bids and those subgroups form the categories of a latent class. 